\title{
LA CRISIS ECONÓMICA Y EL PRINCIPIO DE "ADECUACIÓN A LAS DECISIONES POLÍTICAS" COMO NUEVO CANON DE CONSTITUCIONALIDAD. LÍMITES A LA INTERPRETACIÓN CONSTITUCIONAL
}

\author{
The Economic Crisis and the Principle of \\ "Adapting to Political Decisions" as a New Canon of \\ Constitutionality. Limits to Constitutional Interpretation
}

\author{
JUAN MANUEL GOIG MARTÍNEZ \\ Universidad Nacional de Educación a Distancia \\ juanmgoig@der.uned.es
}

Cómo citar/Citation

Goig Martínez, J. M. (2016).

La crisis económica y el principio de "adecuación a las decisiones políticas" como nuevo canon de constitucionalidad. Límites a la interpretación constitucional. Anuario Iberoamericano de Justicia Constitucional, 20, 117-158.

doi: http://dx.doi.org/10.18042/cepc/aijc.20.05

Resumen

La labor de interpretación constitucional, en especial la labor interpretativa en materia de derechos y libertades, debe someterse a una serie de pautas tendentes a su

1 Profesor titular de Derecho Constitucional de la Universidad Nacional de Educación a Distancia (España), acreditado al cuerpo de catedráticos. También es profesor de máster en varias universidades latinoamericanas. Especialista en derecho constitucional latinoamericano, ha impartido cursos y seminarios en Venezuela, Cuba, Ecuador, República Dominicana, Guatemala, México, Grecia, Portugal y Francia. Es autor de varios artículos en revistas científicas de impacto internacional; ha elaborado varias monografías y ha participado en multitud de obras colectivas, en algunas como coordinador. En el ámbito investigador, sus principales líneas de investigación son: derechos humanos, protección de los inmigrantes, derechos del menor, políticas de igualdad, e interpretación constitucional. 
optimización. La razonabilidad es una pauta de interpretación sustantiva, en tanto método interpretativo de validez de las normas jurídicas, que adquiere un perfil esencial en su relación con las reglas de proporcionalidad y ponderación. Estas reglas, junto con el respeto al contenido esencial, se convierten en canon de constitucionalidad. La labor interpretativa está sometida a unos límites cuya trasgresión implica violación constitucional, por lo que la fijación de los criterios que aplicar en materia interpretativa, debe estar sometida al canon constitucionalmente establecido. El presente estudio tiene como objeto la determinación de la crisis económica española puede ser alegada como canon de constitucionalidad en materia interpretativa.

\section{Palabras clave}

Interpretación constitucional; razonabilidad; proporcionalidad; ponderación; crisis económica.

\section{Abstract}

The work of constitutional interpretation, in particular the interpretative work on rights and freedoms, should be subject to a set of guidelines aimed at optimization. The reasonableness is a pattern of substantive interpretation, as interpretive method of validity of the legal rules, which acquires a profile essential in relation to the rules of proportionality and weighting. These rules, together with respect for the essential content, become canon of constitutionality. The interpretive work is subject to limits whose transgression implies constitutional violation, by what criteria to apply in interpretive material, fixing must be subject to the constitutionally established canon. The present study has as object the determination of the Spanish economic crisis may be alleged as a canon of interpretation regarding constitutionality.

\section{Keywords}

Constitutional interpretation; reasonableness; proportionality; weighting and economic crisis. 


\section{SUMARIO}

I. SOBRE INTERPRETACIÓN CONSTITUCIONAL. II. INTERPRETACIÓN CONSTITUCIONAL E INTERPRETACIÓN DE LOS DERECHOS: 1. La interpretación de los derechos; 2. Progresividad de los derechos e interpretación evolutiva o progresiva. III. EL CANON DE CONSTITUCIONALIDAD. CONTENIDO ESENCIAL, PROPORCIONALIDAD, RACIONALIDAD Y PONDERACIÓN: 1. Razonabilidad, proporcionalidad y ponderación. IV. CRISIS ECONÓMICA Y POLÍTICAS PÚBLICAS COMO NUEVO CANON DE CONSTITUCIONALIDAD: 1. Una limitación en los criterios interpretativos. V. BIBLIOGRAFÍA

\section{SOBRE INTERPRETACIÓN CONSTITUCIONAL}

La interpretación jurídica constituye uno de los procesos más importantes e interesantes en el quehacer jurídico puesto que a través de la interpretación se "explica el sentido de una ley, decisión o acto" (Capitánt, 1930: 329). En el caso de la constitución, su interpretación adquiere especial importancia pues a través de ella se busca dar un sentido a las normas fundamentales que organizan la convivencia política de un país. Además, dada su peculiar característica de norma suprema del ordenamiento jurídico, de su interpretación depende la vigencia de las demás normas (Betti, 1975: 95).

La interpretación constitucional tiene ciertos rasgos diferenciadores de la realizada en otras normas del ordenamiento, en primer lugar porque la naturaleza de los diversos conceptos normativos — constitución y leyes- es distinto (Aragón, 1986: 119), pero también porque la interpretación constitucional parte de un estatuto jurídico de lo político (Canosa, 1988). En segundo lugar porque la interpretación de la constitución no consiste, en la mayoría de los casos, en decidir un caso sometido a apreciación jurisdiccional, sino que supone fijar reglas de concretización válidas, y además, respecto a la influencia del elemento temporal, la interpretación ha de permitir la actualización constitucional, pero sin pasar de unos límites determinados, puesto que sin admitirse una validez absoluta, tampoco cabe que la interpretación se so- 
meta a la orientación política del momento. Por último, debe buscar un ajuste entre ambas posiciones, y este ajuste debe estar basado en el conocimiento de la realidad social. Como acertadamente ha indicado Alzaga (2014), el carácter de norma suprema de la constitución, determina que la técnica interpretativa constitucional no pueda ser la misma que la del resto de ramas del derecho. La constitución, además de reglas formales de contenido muy preciso, ha incorporado valores, principios, mandatos al legislador, compromisos y la idea de que debe practicarse una política asentada en el pluralismo político y que respete ciertos valores, por lo que ofrece un campo a la interpretación distinto al intérprete de la legislación ordinaria.

La trascendencia de la interpretación constitucional sólo se explica desde la interrelación entre la constitución y el ordenamiento jurídico, y por ello, la interpretación constitucional adquiere unos perfiles propios. Pero la constitución no es un cuerpo dogmático cerrado en sí mismo que se impone como una verdad revelada y única sobre el conjunto de los operadores jurídicos, sino el resultado de un proceso de conciliación de intereses que se desarrolla y se extiende para renovar, de manera constante, esa conciliación y pacificación social (Balaguer, 1997: 24).

La interpretación constitucional es ejercida de manera primordial en España por el Tribunal Constitucional (TC), que se define por su propia ley como "el intérprete supremo de la Constitución»", y aunque ser el intérprete supremo no significa ser el único, sí es cierto que su interpretación invadirá e influirá en la que realizan los otros órganos que comparten con él la tarea. Lo que el TC hace al dictar sentencias, es interpretar las normas jurídicas y muy especialmente la norma constitucional, lo que da lugar a que se produzca una integración del sistema normativo, se cubran lagunas y se

2 Desde un punto de vista estrictamente normativo, la fuerza vinculante de la doctrina del TC se deriva de un conjunto de preceptos incluidos, tanto dentro de la propia Constitución, como en la ley orgánica de su desarrollo. El art. 164.1 de la Constitución establece el valor y eficacia general erga omnes de todas las sentencias de inconstitucionalidad y "todas las sentencias que no se limiten a la estimación subjetiva de un derecho", afirmación que se repite en el art. 38,1 de la Ley Orgánica del Tribunal Constitucional (en adelante LOTC) al declarar que dichas sentencias "vincularán a todos los poderes públicos y a todos los ciudadanos», entre ellos a jueces y tribunales. El art. 40.2 LOTC atribuye a la jurisprudencia constitucional un valor corrector de la jurisprudencia ordinaria, al disponer que «en todo caso, la jurisprudencia de los tribunales de justicia recaída en leyes, disposiciones o actos enjuiciados por el Tribunal Constitucional, habrá de entenderse corregida por la doctrina derivada de las sentencias y autos que resuelvan los recursos y cuestiones de inconstitucionalidad». 
cree seguridad jurídica, todo ello con sujeción a una serie de principios definidos por la propia Constitución y por la actuación del TC, que han venido a convertirse en límites a la actividad interpretadora de la Constitución, y que son cifrados por Pérez Royo (1997: 146) como: principio de unidad de la Constitución; principio de concordancia práctica; principio de corrección funcional entre los poderes del Estado diseñados por la Constitución; principio de la función integradora que posee la Constitución, y principio de la fuerza normativa de la Constitución, puesto que no se puede olvidar que el TC no es un árbitro llamado a dirimir contiendas según su leal saber y entender, sino que es un órgano constitucional que en su actividad actúa con sometimiento a la Constitución y a su ley orgánica, que actúan como límites.

El TC es el intérprete supremo de la Constitución, no el único, y su labor implica «interpretación constitucional», y, por supuesto, «interpretación conforme a la Constitución», en el sentido de que no es la Constitución la que debe ser interpretada en conformidad consigo misma sino con las normas infraconstitucionales (Alfonso, 2005: 4), pero teniendo en consideración: a) que aunque la interpretación conforme a la Constitución sea una interpretación de la ley, el parámetro es la Constitución; y b) que al definir a la Constitución como parámetro para saber cómo debe interpretarse la ley, no se puede evitar interpretar, aunque sea en forma mínima, a la propia Constitución.

La importante labor de interpretación constitucional, no puede, sin embargo, apartarse del estudio de sus límites, y para ello debe partirse de la responsabilidad del TC en el ejercicio de las funciones tan sensibles puestas a su cargo, pues no existe control alguno sobre este, ni el TC asume la obligación de rendir cuentas en la forma como las ha ejercido.

En el ámbito de la interpretación constitucional, el TC debe tener prohibido usurpar funciones que la Constitución atribuye a otros órganos mediante la creación de normas y principios que no se reconduzcan a ella. Tampoco debe desequilibrar su interpretación de los principios y de las finalidades que el orden jurídico persigue (certeza y seguridad jurídica), y no autolimitarse, dejando que el activismo judicial sea desbordado (trazar una frontera entre el derecho y la política). El TC tiene como límites: su propia competencia, que primordialmente gira en torno a la interpretación de la Constitución, su defensa y el control de la constitucionalidad de las leyes y actos; el respeto a las cláusulas contenidas en la Constitución, y el respeto de los principios y valores, y los derechos y libertades en que se manifiestan (Carpizo, 2009: 57 y ss). 


\section{INTERPRETACIÓN CONSTITUCIONAL E INTERPRETACIÓN DE LOS DERECHOS}

La idea de que la posición jerárquica de la constitución y su naturaleza exigen un tratamiento especial en su interpretación, adquiere, en materia de interpretación de los derechos, un carácter especial (Linares, 1998).

El objeto principal de las constituciones, además de la definición y organización del ejercicio del poder, es la garantía del principio de libertad, es decir, los derechos y libertades enunciados constitucionalmente, por lo que la constitución debe ser interpretada con el propósito de hacer prevalecer el principio de libertad de los gobernados, que, además, actúa como límite al poder de los gobernantes.

La proclamación inicial del art. 1.1 de la Constitución española (CE) y su estrecha relación con el art. 10.1 al señalar que la dignidad de la persona y los derechos inviolables que le son inherentes son el fundamento del orden y la paz social, supone situar a los derechos y libertades en una posición central dentro del orden jurídico-político, y los contenidos enumerados en el art. 10.1, principalmente la dignidad de la persona y los derechos inherentes a ella, se convierten en la piedra angular del orden constitucional.

Los derechos fundamentales son los componentes estructurales básicos, tanto del conjunto del orden jurídico objetivo como de cada una de las ramas que lo integran, en razón de que son la expresión jurídica de un sistema de valores que, por decisión del constituyente, han de informar el conjunto de la organización jurídica y política

Los derechos humanos suponen la concreción de las exigencias derivadas de la dignidad, la libertad y la igualdad, y su reconocimiento, proclamación y tutela constituyen un elemento necesario a la propia definición estatal como Estado social y democrático de derecho. Los derechos, en su acepción subjetiva, se mantienen y manifiestan como garantías de la libertad del individuo, pero junto a esta dimensión subjetiva, los derechos también despliegan una dimensión objetiva a partir de la cual su contenido deberá ponerse a disposición de la consecución de los fines y valores constitucionalmente proclamados.

Una consecuencia básica de la derivación de los derechos y de la posición central que ocupan en el orden jurídico-político es la obligación que impone a los poderes públicos y a los ciudadanos de dispensarles respeto absoluto, y a los intérpretes constitucionales de interpretar la Constitución de acuerdo con los derechos y libertades por ella enunciados. 


\section{LA INTERPRETACIÓN DE LOS DERECHOS}

La dignidad se configura como un principio fundamental de referencia; razón de ser de los derechos y libertades y del propio Estado social y democrático de derecho proclamado por la Constitución, y como una norma clave entre el preámbulo y el título preliminar y el resto del título I. En el art. 10.1 se integran los principios y valores esenciales de libertad, igualdad y justicia que enuncia el preámbulo y los arts. 1 y 9 del título preliminar, que se positivizan en los derechos y libertades reconocidas en el título I, y que resulta vinculante para todos los poderes públicos (art. 9.1), a los que se impone el deber fundamental de promover las condiciones para que la libertad y la igualdad del individuo sean reales y efectivas; remover los obstáculos que impiden o dificulten su plenitud, y facilitar la participación de los ciudadanos en distintos sectores de la vida estatal (art. 9.2) (Ruiz-Giménez, 1997: 57 y ss.).

El art. 10.1 viene a colocar la dignidad de la persona como la fuente de todos los derechos, de forma que todos y cada uno de los derechos que la Constitución proclama en su título I son inherentes a la persona y a su dignidad radical, y todos contribuyen al desarrollo integral del ser humano, lo que nos lleva a determinar que la dignidad humana operará como parámetro, tanto para la determinación del contenido esencial de los derechos fundamentales, como para la realización de una interpretación adecuada de los derechos fundamentales por el legislador, por el Tribunal Constitucional y por todos los operadores del ordenamiento jurídico (Fernández Segado, 1995: 66 y ss.).

La posición central que ocupan los derechos y libertades en nuestro ordenamiento constitucional obliga a que las reglas de interpretación de los mismos adquieran perfiles especiales, reglas que podrán ser sintetizadas de la siguiente manera:

a. El principio pro homine tiene dos variantes principales: de un lado la preferencia interpretativa, según la cual el intérprete ha de preferir la interpretación que más optimice un derecho fundamental (y que se plasma en los subprincipios de favor libertatis, de protección a las víctimas o favor debilis, de prohibición de aplicación por analogía de normas restrictivas de derechos, de in dubio pro operario, de in dubio pro reo, de in dubio pro actione, etc.); de otro, la preferencia de normas, de acuerdo con la cual el intérprete, si puede aplicar más de una norma al caso concreto, deberá preferir aquella que sea más favorable a la persona, aunque siempre dentro del respeto de la jerarquía normativa.

b. El principio de mayor protección de los derechos, entiende que la regulación constitucional de los derechos es solamente un estándar mínimo, que puede y debe ser ampliado por los distintos intérpretes que los apli- 
can. Esto involucra no solamente al intérprete judicial, sino también al legislador cuando aprueba leyes o a la Administración Pública cuando expide reglamentos o cuando diseña políticas públicas para dotar de realidad los derechos. Un primer elemento de mayor protección de los derechos se suele encontrar en los tratados internacionales, que constituyen elemento interpretativo de las normas reguladoras de los derechos

c. El tercer principio tiene que tomar en consideración la fuerza expansiva de los derechos, principio que se puede aplicar tomando varias perspectivas, bien en cuanto a la titularidad de los derechos, o en cuanto a la eficacia horizontal y vertical de los derechos.

La interpretación de los derechos humanos supone mucho más que una mera aplicación mecánica de las normas o principios que existen en una situación social particular, y en materia de derechos fundamentales la actividad interpretativa tiene que estar condicionada por los principios de razonabilidad y proporcionalidad. El razonamiento jurídico implica una argumentación en términos de razonabilidad hecha a partir de la ponderación de las reglas que contienen derechos (Galán 2006: 33-55), y con aplicación de la regla de proporcionalidad.

Carpio (2004: 82 y ss.; 100 y ss.) también se refiere a la noción de contenido esencial de los derechos fundamentales y a la técnica de la ponderación, que es la vía de interpretación que mejor se adapta al establecimiento en forma de principios que suelen tener los derechos fundamentales en los textos constitucionales del presente.

Las normas relativas a los derechos humanos se interpretarán otorgando, en todo tiempo, la protección más amplia — principio "pro persona»- $y$, a su vez, establecen que la efectividad de la promoción y garantía de los derechos humanos se hará de conformidad con los principios de universalidad, interdependencia e interacción, indivisibilidad, irreversibilidad y progresividad.

La universalidad se refiere, en primer lugar, a la titularidad de los derechos. Los derechos humanos se adscriben a todas las personas, sin discriminación, y pueden exigirse por todos los seres humanos en cualquier contexto jurídico, político, social y cultural. El concepto de universalidad está problematizado desde la teoría crítica, la sociología jurídica y la antropología jurídica.

La integralidad y la indivisibilidad consideran los derechos como un conjunto. La integralidad plantea una aspiración de que todos los derechos sean reconocidos a todas las personas, sin diferencias ni jerarquías.

Los derechos están vinculados y no existe separación entre ellos. A eso se refiere la interdependencia: la medida en que el disfrute de un derecho en particular o un grupo de derechos depende para su existencia de la realización de otro derecho o grupo de derechos. 
La indivisibilidad niega cualquier separación. Los Estados no están autorizados a proteger y garantizar una determinada categoría de derechos humanos en contravención de otra, sino que todos merecen la misma atención y urgencia.

Por último, la progresividad implica gradualidad y adelanto o progreso. La plena efectividad de los derechos no se logrará de una vez y para siempre, sino que se trata de un proceso que supone definir metas a corto, mediano y largo plazos. La progresividad implica, de entrada, el establecimiento de un estándar mínimo a partir del cual se considera en aumento la implementación del derecho; y por otro lado, la prohibición de regresividad, es decir que una vez logrado el avance en el disfrute de ciertos derechos, el Estado no podrá disminuir el nivel alcanzado.

\section{PROGRESIVIDAD DE LOS DERECHOS E INTERPRETACIÓN EVOLUTIVA O PROGRESIVA}

La garantía de los derechos humanos conforme al principio de progresividad, implica necesariamente que la interpretación de sus normas reguladoras debe realizarse de la manera más favorable al ejercicio y goce de los derechos. El principio de que los derechos humanos deben alcanzarse progresivamente determina que los poderes públicos tienen la obligación inmediata de asegurar las condiciones que permitan gradual y constantemente la plena realización de estos derechos ${ }^{3}$.

Lograr progresivamente la plena efectividad de los derechos reconocidos, incorpora una obligación inmediata de respetar y garantizar todos los derechos pertinentes y requiere un dispositivo de flexibilidad necesaria que refleje las realidades del mundo real y las dificultades que implica para cada país el asegurar la plena efectividad de los derechos ${ }^{4}$.

Este principio de progresividad se integra con el principio de "primacía de la disposición más favorable a la persona humana» o "cláusula de individuo más favorecido». Un complemento del principio de progresividad es la irreversibilidad: la imposibilidad de que se reduzca la protección ya acordada, como consecuencia del criterio de conservación del sistema más favorable.

También la interpretación progresiva exige que deban tomarse en cuenta, tanto las condiciones y necesidades existentes al momento de la sanción del precepto constitucional, como las que se advierten al llevar a cabo su inter-

3 STEDH, Caso Airey $v$. Ireland, de 9 octubre de 1979.

4 Comité de Derechos Económicos, Sociales y Culturales, observación general núm. 3, párr. 9. 
pretación y aplicación, ya que toda constitución constituye un instrumento permanente de gobierno, cuyos preceptos aseguran la estabilidad y certeza necesarias para la existencia del Estado y del orden jurídico. Por tanto, ante un precepto constitucional que por su redacción permite la adecuación de su sentido a determinadas circunstancias, ya sea jurídicas o de otra índole, para fijar su alcance, sin imprimirle un cambio sustancial, debe atenderse precisamente a la estabilidad o modificación que han sufrido esas circunstancias, sin que con ello sea válido desconocer o desnaturalizar los propósitos que llevaron al constituyente a establecer la disposición en estudio.

\section{EL CANON DE CONSTITUCIONALIDAD. CONTENIDO ESENCIAL, PROPORCIONALIDAD, RACIONALIDAD Y PONDERACIÓN}

La justicia o injusticia que pueda significar la solución de las distintas controversias que involucren derechos fundamentales, depende de la actividad interpretativa que se lleve a cabo con el objeto de definir, en cada caso concreto, cuál es el contenido que protege o garantiza el derecho fundamental que está en juego. Se trata de una actividad interpretativa tanto de la norma como de los hechos, que consiste en determinar si el acto o los actos que se enjuician en un caso caen dentro o fuera del ámbito protegido por un derecho a fin de otorgarles o no protección constitucional.

La determinación del contenido de un derecho ayuda a establecer si una acción o una omisión del poder público —en particular del legislador-, es constitucionalmente legítima o, por el contrario, debe ser rechazada por constituir una restricción o afectación indebida de ese contenido.

La propia idea del Estado social de derecho convierte al art. 9.2 en una norma que fundamenta el contenido y la eficacia de los derechos y libertades constitucionales y su posición en el sistema constitucional español, pero además también fundamenta la actuación de los poderes públicos. Los poderes públicos deberán orientar su actuación a hacer reales y efectivos los derechos y libertades reconocidos en la Constitución, de manera que, como ha afirmado Häberle $(1990)^{5}$, la efectividad de los derechos y libertades se convierte en un deber constitucional para los poderes públicos, y de este deber constitucional se deriva, también, que los derechos y libertades hayan dejado de ser considerados solamente como límites a la actuación de los poderes públicos, pues al encomendar a los poderes públicos promover las condiciones para una eficaz

5 La teoría completa de Häberle puede verse en Die Weseeengehaltsgarantie des Art. 19.Abs. 2 Grundgesetz, Heidelberg, Müster, 1983, 3ª . ed. 
y real libertad, refleja la dimensión social del Estado de derecho e impone determinados cometidos a sus poderes.

Otra de las consecuencias directas de la posición central que los derechos y libertades ocupan en el orden jurídico político del Estado español como Estado social y democrático de derecho, es la obligación que se impone a los poderes públicos de respeto absoluto y que no solo se infiere del art. 9.1, sino que la Constitución manifiesta expresamente en el art. 53.1, al afirmar en su primer inciso que «los derechos y libertades reconocidas en el Capítulo II del presente Título vinculan a todos los poderes públicos».

La vinculación que el art. 53.1 reconoce de los derechos y libertades a los poderes públicos, no puede ser entendida ni de forma restrictiva respecto a lo preceptuado en el art. $9.1 \mathrm{ni}$ de forma restrictiva respecto al contenido de la obligación que para los poderes públicos suponen los derechos y libertades. La vinculación que impone el art. 53.1 puede ser observada como una «vinculación especial», es decir, los poderes públicos están sometidos a la Constitución en general, y en especial a los derechos y libertades que reconoce la Constitución en el capítulo II del título I porque los derechos y libertades constituyen el pilar principal del Estado, es decir, manifiestan la finalidad propia de toda limitación del poder constitucional en un Estado de derecho que consiste en proteger la libertad y la igualdad de las personas a través de los derechos y libertades.

Respecto a la posible restricción que el precepto puede suponer con relación al contenido del art. 9.1, no han faltado en la doctrina (Gavara, 1994: 340) quien manifieste la mayor intensidad de la vinculación frente a la sujeción: mientras que la sujeción implica la obligación de respetar los preceptos constitucionales no realizando conductas o adoptando actos en contra de la Constitución, la vinculación implicaría, además de la obligación de respeto, el deber de cumplir y hacer cumplir los derechos, creando una obligación de potenciar la efectividad en el cumplimiento de los derechos y libertades. Esto supone la vinculación de los poderes públicos, su obligación de hacer reales y efectivos los derechos sobre los que se proyecta el art. 53.1, por lo que su estrecha relación y complementariedad con el art. 9.2 está asegurada.

La vinculación que se impone a los poderes públicos respecto a los derechos y libertades lo es para todos los poderes públicos. Sin embargo, cuando el art. 53.1 proclama que «sólo por ley, que en todo caso deberá respetar su contenido esencial, podrá regularse el ejercicio de tales derechos y libertades», se deriva un plus de vinculación respecto al poder legislativo, y ese plus de vinculación se residencia en el respeto al contenido esencial.

La garantía del contenido esencial que proclama la Constitución se deriva del art. 10.1, cuando eleva a la categoría de fundamento del orden político y de la paz social los derechos inherentes a la dignidad humana. 
El art. 9.2 impone la obligación de promover las condiciones para que la libertad y la igualdad, y los derechos y libertades que concretan las exigencias de libertad e igualdad, sean reales y efectivas, determinando la necesidad de legislar en favor de la efectividad, protección y practicidad de los derechos, y estableciendo cauces e instrumentos necesarios para dicha efectividad práctica. La actuación del legislador en el ámbito de los derechos y libertades exige un aspecto positivo de potenciación para un desarrollo adecuado y efectista del contenido de estos derechos y libertades.

De esta forma, la garantía del contenido esencial que preceptúa el art. 53.1 no actuaría sólo como un límite a la actuación normativa del legislador, como tradicionalmente ha sido entendida, y el contenido esencial no sería el último parámetro defensivo o el límite de los límites, sino que se constituiría, además, en el instrumento más adecuado para dotarles de la eficacia necesaria. Ello permitiría, por ejemplo, establecer de una forma justa los mecanismos adecuados para un efectivo ejercicio de derechos y libertades que lo puedan exigir. En otros supuestos, la actuación del legislativo consistiría en conformar y precisar el contenido del derecho, dando cumplimento a la certeza que exige el principio constitucional de seguridad jurídica, o incluso ampliar el ámbito constitucional del derecho o la libertad en cuestión. Sin embargo, en esta labor de conformación y precisión, el legislativo está sometido a su contenido constitucionalmente declarado. Tampoco puede consistir en una actividad delimitadora que imponga una serie tal de formalismos que impida el ejercicio de un derecho o de una libertad que es directamente ejercitable y de eficacia directa sin necesidad de desarrollo legislativo.

Los poderes públicos, en especial el legislador estatal que es el único capacitado por vía del art. 53.1 para regular el ejercicio de los derechos y libertades, están vinculados a los derechos y libertades constitucionales. Por ello, cuando regule, que no limite, un derecho o una libertad, lo que la Constitución le ordena «no es que se abstenga de afectar al contenido esencial de los derechos, sino que al ejercer la regulación del ejercicio de los derechos, respete su contenido esencial, es decir, lo desarrolle adecuadamente y le dispense una protección eficaz» ( Martínez, 1997: 85), y ello implica un efecto positivo y progresivo en los derechos y libertades que puede provenir del mandato del art. 9.2. Así, cuando la Constitución remite en los diversos preceptos en los que se reconocen derechos y libertades a su regulación por ley, lo que está haciendo es imponer al legislador la necesidad de desarrollar positivamente y de la manera más adecuada al contenido esencial de los derechos, el contenido constitucionalmente declarado. 
La idea de contenido esencial trata de que el desarrollo de un derecho no destruya su contenido material — su núcleo básico o contenido esencial ${ }^{6}$-, convirtiéndolo en un derecho puramente formal. Surge para evitar la excesiva restricción de los derechos y para que las limitaciones que se les impongan vacíen su contenido normativo.

Existen dos teorías sobre el contenido esencial de los derechos fundamentales: la absoluta y la relativa (Lothar, 2009). La teoría absoluta concibe el ámbito normativo de los derechos fundamentales como el área de dos círculos concéntricos, y entiende la parte formada por el círculo interior como un núcleo fijo e inmutable de esos derechos. Cualquier afectación a su respeto sería ilícita ${ }^{7}$. Para la teoría relativa, el contenido esencial de los derechos no es preestablecido y fijo, sino determinable sólo casuísticamente en atención de las circunstancias del caso y tras ponderarse los beneficios y perjuicios que se

6 Sus referentes históricos son el art. 19.2 de la Constitución alemana de 1949: «1. Cuando de acuerdo con la presente Ley Fundamental un derecho fundamental pueda ser restringido por ley o en virtud de una ley, esta deberá tener carácter general y no estar limitada al caso individual. Además, la ley deberá mencionar el derecho fundamental indicando el art. correspondiente. 2. En ningún caso, un derecho fundamental podrá ser afectado en su contenido esencia». Como precedente y modelo de la garantía del contenido esencial del art. 19.2 LFB puede citarse el art. 63.1 de la Constitución de Hessen (1946). La construcción tal vez más relevante sobre la esencialidad y sobre el contenido esencial de los derechos fundamentales tuvo lugar en la famosa Sentencia Solange II del Tribunal Constitucional federal alemán (BVerfGE 73, 339, 387 - Solange II; posteriormente, E 118, 79, 95). De igual manera, el art. 17 del Convenio Europeo de Derechos Humanos prohíbe cualquier acto que pueda llevar a la destrucción de los derechos fundamentales, y la Carta de los Derechos Fundamentales de la Unión Europea (Niza 2000) determina que cualquier limitación de los derechos reconocidos en ese texto debe ser establecida por ley y respetar su contenido esencial.

7 Esta teoría relativiza los derechos fundamentales, puesto que al distinguir dentro de un derecho entre un núcleo esencial y uno accesorio, abre cualquier posibilidad de restricción para esta última parte. El riesgo se acrecienta con la inevitable dificultad de determinar ese núcleo absoluto. La Constitución no distingue entre contenidos accidentales y principales, sino que reconoce los derechos fundamentales en su integridad. La distinción entre concepción absoluta y relativa del contenido esencial tiene consecuencias de orden práctico. Si se adopta la teoría absoluta, cualquier injerencia en el contenido esencial es inconstitucional, aunque sea solo individualizado, el contenido es uno y siempre el mismo, y puede ser establecido por cada derecho fundamental. Si se adopta la teoría relativa, la afectación es posible en el caso concreto, pues no se afecta al derecho fundamental en cuanto derecho subjetivo considerado de manera objetiva y abstracta. 
produzcan en él, tanto para el derecho intervenido como para el bien protegido a través de su limitación. El principio de proporcionalidad se adscribe, como es evidente, a la teoría relativa sobre el contenido esencial de los derechos fundamentales (Sánchez, 2007: 111 y 112).

Para la teoría relativa ${ }^{8}$, toda restricción de los derechos fundamentales exige una justificación, que puede figurar explícita en la constitución o derivarse implícitamente. El contenido esencial de un derecho fundamental resulta de su ponderación con aquellos bienes o derechos que justifican su limitación. En consecuencia, no existe un núcleo permanente identificable como contenido esencial del derecho. La única razón aceptable en la justificación del límite o injerencia del derecho fundamental, exige el juicio de constitucionalidad.

Este juicio se realiza mediante un examen de razonabilidad, denominado por la doctrina alemana "principio de proporcionalidad en sentido amplio", que tiene los siguientes elementos:

a. El examen de adecuación de la medida limitadora al bien que mediante ella se pretende proteger.

b. La falta de una alternativa menos gravosa y la consecuente necesidad de la lesión del derecho para el fin pretendido.

c. El principio de proporcionalidad en sentido estricto que busca valorar si la lesión es proporcionada al fin que con ella se pretende.

El contenido esencial se identifica con la idoneidad de la limitación de un derecho en función de su protección de otros bienes constitucionales.

En cuanto integrantes del contenido constitucionalmente protegido, cabría distinguir, de un lado, un contenido no esencial, esto es, claudicante ante los límites proporcionados que el legislador establezca a fin de proteger otros derechos o bienes constitucionalmente garantizados y, de otra parte, el contenido esencial, absolutamente intangible para el legislador; $y$, extramuros del contenido constitucionalmente protegido, un contenido adicional formado por aquellas facultades y derechos concretos que el legislador quiera crear im-

8 También esta teoría ha sido objeto de crítica. La teoría relativa parece cambiar el sentido del art. 53.1 y convertirlo en una mera garantía formal. El juicio de constitucionalidad de limitación a un derecho fundamental descansa únicamente en los fines perseguidos sin que se examine al propio derecho lesionado. El resultado es que la cláusula del contenido esencial es solo declarativa pues no añade nada al establecimiento constitucional del derecho. Aunque no existiera, toda limitación de un derecho fundamental requerirá una justificación, que además es válida si está basada en otro bien constitucionalmente protegido. 
pulsado por el mandato genérico de asegurar la plena eficacia de los derechos fundamentales (Medina, 1996: 41).

Puesto que el contenido esencial de un derecho fundamental es la concreción de las esenciales manifestaciones de los principios y valores que lo informan, su determinación requiere un análisis sistemático de este conjunto de bienes constitucionales, en el que adquiere participación medular el principio-derecho de dignidad humana, al que se reconducen, en última instancia, todos los derechos fundamentales de la persona.

El contenido esencial de un derecho fundamental y los límites que sobre la base de este resultan admisibles, forman una unidad (Häberle, 1997: 117), por lo que —en la ponderación que resulte necesaria a efectos de determinar la validez de tales límites- cumplen una función vital los principios de interpretación constitucional de «unidad de la constitución»y de "concordancia práctica», cuyo principal cometido es optimizar la fuerza normativo-axiológica de la constitución en su conjunto.

«El contenido esencial es [...] un concepto jurídico, capaz de ser depurado y perfilado técnicamente a fin de hacer operativo el límite jurídico que expresa en el proceso de aplicación del texto constitucional» (Parejo, 1981: 169 a 193), que ha sido definido de diversas maneras.

Implica la determinación de un contenido material sustraído al poder para, al establecer este núcleo intangible, eliminar todas las posibilidades que, amparadas en la legislación, pudieran atentar ya no sólo contra derechos fundamentales singulares, sino contra el conjunto de los mismos a través de la violación de uno de ellos (García, 1979: 111-113).

«Señala una frontera que el legislador no puede traspasar, delimita un terreno que la ley limitadora no puede invadir sin incurrir en inconstitucionalidad [...] es límite de los límites porque limita la posibilidad de limitar, porque señala un límite más allá del cual no es posible la actividad limitadora de los derechos fundamentales y de las libertades públicas» (Martín-Retortillo y De Otto, 1988). Pero es algo más, porque es preciso respetar ese contenido esencial siempre y en todo caso, aunque su actuación no tenga por objeto limitar la libertad, sino regular el ejercicio de uno de aquellos derechos que generan obligaciones de contenido positivo (Prieto, 1984: 463-471).

«El contenido esencial es la expresión jurídico-positivizada del valor intrínseco de cada uno de los derechos fundamentales y libertades públicas que reconoce la Constitución española, resultado de la conjunción entre el valor de la dignidad humana («fundamento del orden político y de la paz social») y el núcleo radical propio de cada derecho o libertad que tiene que ver con sus manifestaciones particulares (internas y externas o relativas a su ejercicio)» (Lorenzo, 1996: 36). 
La importancia del contenido esencial, plantea la necesidad de su delimitación y quién tiene encomendada esta tarea, pero en la idea de que determinar y crear son dos procesos diferentes. El contenido esencial de los derechos fundamentales y libertades públicas es anterior a su regulación constitucional.

Respecto a quién corresponde su delimitación, parece que es al legislador, pero la Constitución no encarga tal tarea al legislador, sino que le otorga la potestad para regular el ejercicio del derecho fundamental.

Regular el ejercicio no es lo mismo que determinar el contenido del derecho o libertad en cuestión. Regulación implica una afectación normativa a través de la cual se establecen modos, condiciones, formas y limitaciones-restricciones del ejercicio de los derechos, la que se despliega a partir del contenido del derecho, tal como resulta de la construcción dogmática del mismo a través de su definición abstracta.

El legislador está obligado a respetar y tiene prohibido constitucionalmente afectar el contenido esencial de los derechos. Dicho contenido esencial se instituye como la barrera constitucional insuperable e infranqueable en la tarea de establecer posibles limitaciones de los derechos, constituye un límite al poder de limitar los derechos, y se conforma así como la dimensión constitucional del derecho proveniente de la tradición jurídica que se debe preservar, pero sobre todo, es un elemento de desarrollo y extensión.

En tal caso, tiene mucho que decir el TC, como «intérprete supremo de la Constitución», y a él le corresponderá desvelar ese contenido en cada caso concreto, pero interpretar no equivale a determinar el "contenido» del contenido.

Delimitar un derecho es establecer su contenido (haz de facultades, garantías y posibilidades de actuación) y sus fronteras o límites. En otras palabras, delimitar es definir el ámbito de realidad protegido por el derecho, lo que determina sus contornos.

Para delimitar el contenido del derecho deben tenerse presente dos elementos: el identificar el ámbito de la realidad al que se alude y fijar lo que se entiende por este, y el tratamiento jurídico contenido en el precepto que reconoce el derecho, fijando su contenido y el alcance que se da a su protección constitucional (De Otto, 1988).

El valor de esta garantía reside en ofrecer al juez constitucional un criterio para fiscalizar las leyes de desarrollo, ya que se trata de una garantía y no de una mera ayuda a la labor judicial; más aún, es un punto de referencia para el TC porque previamente es una prohibición al legislador (Baura, 1978: 700 yss).

No corresponde al juez constitucional revisar la oportunidad o conveniencia — criterios típicamente "políticos»— a manera de un superior jerárquico, especialmente si fueron tomadas dentro de sus márgenes constitucio- 
nales de competencia; su labor consiste exclusivamente en decidir sobre la validez de un acto según esté prohibido o permitido por la ley fundamental, determinando si transgredieron los límites (explícitos o implícitos) que les impone la Constitución.

El juez constitucional utiliza unas reglas que no operan en el vacío, sino en la atención a un parámetro constitucional: la optimización de los derechos fundamentales.

\section{RAZONABILIDAD, PROPORCIONALIDAD Y PONDERACIÓN}

Para el constitucionalismo democrático, la dignidad y los derechos inherentes al ser humano son su sentido último. Más aún, la constitución misma fue creada con el objeto de garantizarlos y protegerlos frente al poder, y por ello tienen un valor absoluto para el constitucionalismo (Pereira, 2006: 259), sin que ello signifique que los derechos sean ilimitados.

No obstante, que los derechos tengan un contendido y límites no significa que en la realidad no se presenten dudas sobre el alcance o contenido del derecho. Ello implica una labor definidora por parte de los poderes públicos, que, entre otras cosas, conlleva la necesidad de una regulación y reglamentación normativa por parte del legislador. Pero dicha actuación normativa debe ser razonable. "Toda limitación autorizada por la Carta Fundamental que realice el legislador de los derechos fundamentales, además de la necesidad de que esté expresamente autorizada por la Carta Fundamental, debe ser justificada, no pudiendo ser arbitraria» (Nogueira, 2008: 128).

Todo ello supone dos exigencias: una de ellas es formal — que la regulación o reglamentación provenga de los órganos competentes y que se ajuste a las formalidades y procedimientos contemplados en la Constitución-, y la otra material o de fondo - que los objetivos de la norma y los medios empleados en esta sean acordes con la Constitución y respondan a cierta «racionalidad», en particular con aquel hipotético núcleo irreductible que constituye a cada derecho o libertad, y que permite identificarlos unos de otros: su contenido esencial- (Martínez, 2011: 199 a 226).

«La peculiaridad de la tarea jurídica consiste en que lleva consigo un ejercicio de razón práctica con efectos vinculantes» (Ollero, 1996: 434).

El control de constitucionalidad implica necesariamente un juicio de razonabilidad, al punto que esta "ha venido a constituirse en un sinónimo de constitucionalidad, pues lo razonable es lo ajustado a la Constitución, no tanto a la letra como a su espíritu, y lo irrazonable es lo que conculca la Constitución, lo inconstitucional» (Haro, 2001: 179 a 186).

La idea de razonabilidad abarca la proporcionalidad, siendo esta una consecuencia o manifestación de aquella. En esencia, el principio de razona- 
bilidad apunta a la interdicción de actuaciones o intervenciones excesivas por parte de los poderes públicos, y se ha convertido en un principio constitucional de protección de los derechos fundamentales.

La razonabilidad es una pauta de interpretación sustantiva, en tanto método interpretativo de validez de las normas jurídicas (Maldonado, 2012/2013: 139-174).

Si bien razonabilidad y proporcionalidad son conceptos parecidos, que apuntan al mismo objetivo de evitar la arbitrariedad, lo cierto es que un estudio más detenido de ambos lleva a concluir que estricta y formalmente no son lo mismo (Sapag, 2008: 157 y ss) ${ }^{9}$, aunque sí existe una relación entre ambos principios, de género a especie. Ello porque la idea de razonabilidad abarca la proporcionalidad, siendo esta una consecuencia o manifestación de aquella, mediante la cual se puede llegar a determinar si una actuación estatal es o no jurídicamente la más adecuada para perseguir un determinado fin. En el juicio de proporcionalidad se trata de determinar hasta qué punto resulta constitucionalmente admisible una intervención estatal, o lo que es lo mismo, cuál es el grado de intervención compatible con el respeto a los derechos. Ello

9 Como señala Sapag, el origen del principio de razonabilidad se encuentra en el derecho anglosajón, y se vincula al denominado due process of Law, que hunde sus raíces en documentos medievales, como la Carta Magna de 1215. En su concepción original implica la idea de que para que los actos de los poderes públicos sean válidos deben observarse ciertas reglas y procedimientos. Si bien desde sus orígenes el debido proceso se entendió como un principio de carácter más bien procesal o adjetivo, las cosas cambian a partir de la interpretación que de este principio comenzó a hacer la jurisprudencia norteamericana desde finales del siglo XIX. En 1791, la V enmienda de la Constitución de Estados Unidos había incorporado de manera expresa el principio del due process, al señalar que «nadie estará obligado [...] a declarar contra sí mismo en ningún juicio criminal; ni se le privará de la vida, la libertad o la propiedad sin el debido procedimiento jurídico [...]». Más tarde, en 1868, se introdujo la enmienda $\mathrm{XIV}$, que ratificando la idea del debido proceso, amplía su ámbito de aplicación al señalar que «ningún estado podrá dictar o poner en vigor ley alguna que menoscabe los derechos e inmunidades de los ciudadanos de los Estados Unidos; y ningún estado podrá privar a persona alguna de la vida, la libertad, o la hacienda, sin el debido procedimiento jurídico; ni podrá negar a persona alguna bajo su jurisdicción la igual protección de las leyes». Entre 1886 y 1905, y a partir de las cláusulas sobre due process, la Corte Suprema norteamericana elaboró una doctrina acerca de la razonabilidad de los actos regulatorios del Estado. Pero a partir de 1937, la jurisprudencia comienza a efectuar una distinción a efectos de realizar el control de constitucionalidad de la actividad regulatoria por parte del Estado. 
apunta a eliminar la arbitrariedad, y en tal sentido, el juicio de proporcionalidad supone el de razonabilidad.

El principio de proporcionalidad —o razonabilidad, según sea entendida-, es una de las herramientas metodológicas más importantes del constitucionalismo de nuestro tiempo, que permite superar la aplicación de métodos tradicionales, literalistas y estrechos en la interpretación, apoyando la solidez de las conclusiones jurisdiccionales — y al menos idealmente también la argumentación de otros operadores jurídicos: legislador, Administración Pública- (Bernal, 2005: 544 y 545). La detallada elaboración de sus diversos subprincipios (idoneidad, necesidad y proporcionalidad stricto sensu) ha permitido resolver, al brindar parámetros objetivos, el problema de dar contenido a la volátil idea de "razonabilidad», tan invocada en todos los ámbitos jurídicos, pero más en el constitucional por la indeterminación de sus disposiciones (Carbonell, 2008). La razonabilidad no constituye una fórmula absoluta para la aplicación jurídica; da criterios para ella y tiene un procedimiento bien establecido, pero no son fines en sí mismos, sino que buscan, tendiendo naturalmente a ello, lograr la «igualdad proporcional» entre bienes jurídicos tutelados o tutelables.

La proporcionalidad no es una idea nueva para el derecho, que con diversas modalidades la usa desde mucho tiempo atrás en varios de sus ámbitos $\left(\right.$ Sánchez, 2009) ${ }^{10}$. Pero en el ámbito constitucional adquiere gran relevancia

$10 \mathrm{Al}$ tratar este tema es obligatorio acudir primeramente a la doctrina y jurisprudencia alemanas, pues precisamente en ese país se llevó a cabo la elaboración de los tres subprincipios de la proporcionalidad; el mismo Robert Alexy ha dicho que la garantía del "contenido esencial» de los derechos fundamentales a que se refiere el art. 19.2 de la Constitución germana - y las de otros países como España- es precisamente el cumplimiento del principio de proporcionalidad. El Tribunal Constitucional Federal alemán definió la proporcionalidad lato sensu como de «rango constitucional» y la derivó «del principio de Estado de derecho y también de la esencia misma de los derechos fundamentales». Puede decirse que de Alemania tomó el Tribunal Europeo de Derechos Humanos el principio de proporcionalidad, al que ha dado un frecuente uso y enriquecido con el concepto de «margen nacional de apreciación», que permite cierta amplitud a los Estados — aunque con diversos alcances, siempre hay tal «margen» en la aplicación del principio de proporcionalidad-. Enjuiciando el respeto al derecho de igualdad, este órgano internacional habló de que las medidas estatales distintivas deben tener una «justificación objetiva y razonable» y una «relación razonable de proporcionalidad entre los medios empleados y el fin perseguido». Con explícita inspiración en la anterior sentencia del Tribunal de Estrasburgo y haciendo suyos casi los mismos términos, el Tribunal Constitucional español también adoptó el principio de proporcionalidad. 
por la necesidad de utilizarlo para resolver múltiples problemas —el control de las amplias facultades discrecionales que da la constitución (sobre todo al legislador, pero también a la Administración y la Judicatura); la aplicación del principio de igualdad (y la relevancia de las diferencias para la razonabilidad de una distinción legislativa); el contenido esencial de los derechos fundamentales y los límites de sus posibles restricciones (sobre todo cuando las cláusulas generales constitucionales dejan establecerlas a los " términos que indique la ley») — y los "conflictos» de los derechos fundamentales entre sí y con otros principios constitucionales, e incluso entre reglas derivadas de un solo y mismo principio, cuya solución sin ella sería sencillamente dejada al decisionismo y la arbitrariedad.

Efectivamente, el juicio de proporcionalidad está orientado a resolver conflictos entre derechos, intereses o valores en concurrencia. Lo peculiar del juicio de proporcionalidad es el punto de vista desde el que se procede al examen de la controversia una vez se ha fijado el contexto - las circunstancias del caso-: desde la legitimidad de los fines atendidos por la norma, medida o actuación denunciada, lo que se va a analizar es su utilidad (su idoneidad para alcanzar el fin pretendido), su necesidad (en ausencia de otra alternativa igualmente eficaz y menos problemática) y, por fin, su "proporcionalidad", atendido a su grado de injerencia en un ámbito protegido, así como el carácter y alcance del sacrificio que impone sobre los derechos o intereses afectados. En virtud de este examen se juzgarán inaceptables normas, medidas o actuaciones en la medida en que impongan un sacrificio inútil, innecesario o desequilibrado, por excesivo, de un derecho o interés protegido.

El test de proporcionalidad ha pasado de "principio general» a «canon constitucional», y ha posibilitado el establecimiento de criterios y reglas de alcance relativo, válidos para el caso, sin necesidad de previa delimitación a priori o en abstracto del contenido constitucional del derecho. Esta virtualidad del control de proporcionalidad tiene como efecto la producción de un número considerable de sentencias interpretativas y la generación de una variedad de reglas a propósito de las condiciones del ejercicio de los derechos - restricciones de tiempo y lugar o modo-.

El control de proporcionalidad ha ido restando espacio a la "ponderación a secas", aunque la ponderación es una constante en la práctica de los operadores jurídicos.

La expresión "ponderar» significa "determinar el peso de una cosa», y la «ponderación» se define como la «compensación o equilibrio entre dos pesos». En el ámbito constitucional, la ponderación es el tipo esencial de razonamiento que sopesa derechos de rango constitucional que han entrado en conflicto, frente a los principios y valores constitucionales con el propósito de alcanzar una consecuencia o solución. 
La existencia de una incompatibilidad en concreto o derivada del discurso de aplicación, que es la que se observa con mayor grado y frecuencia en las colisiones de principios (y derechos) constitucionales, resulta la materia propia de la ponderación.

En este punto es relevante destacar la dimensión de peso de los principios constitucionales conforme lo concibió originalmente Dworkin (1999) y posteriormente Alexy (2007: 135 a 138). Las colisiones entre este tipo de normas se superan mediante el llamado juicio de ponderación, consistente en considerar o evaluar el peso o la importancia de cada una de ellas en el caso concreto, tratando de buscar una solución armonizadora que optimice su realización (de ahí la acertada calificación de los principios como mandatos de optimización).

Acercando el término "ponderación» a la óptica jurídica, es posible que la definición que mejor le pertenezca sea aquella que hace referencia a la acción de «considerar imparcialmente los aspectos contrapuestos de una cuestión o el equilibrio entre el peso de dos cosas» (Prieto, 2003: 189), con la finalidad de resolver un conflicto de principios (derechos, bienes jurídicos, intereses, etc.) que suministran justificaciones diferentes y oponibles al momento de adoptar una decisión en un caso concreto.

Desde el punto de vista jurídico, la ponderación implica sopesar derechos que tienen la cualidad de haber entrado en conflicto para alcanzar una solución razonable. En una acepción que podemos denominar estricta, la ponderación es un método para la resolución de ciertas antinomias, que se constituye en un criterio metodológico indispensable para el ejercicio de la función jurisdiccional y para el papel del intérprete constitucional como aplicador y garante de los principios constitucionales, expresados en los derechos, dentro del marco del Estado social y democrático de derecho.

Cuando usamos la ponderación, enfrentamos dos normas tipo principio, pero no para derrotar a una sobre la otra como ocurriría con las reglas, sino para restringir una en favor de otra, otorgándole más poder o más validez en un caso concreto.

Conforme señala Bernal Pulido (2007): «Los ordenamientos jurídicos no están compuestos exclusivamente por reglas, sino que a él se suman los principios y la ponderación es la manera de aplicar los principios y de resolver las colisiones que pueden presentarse entre ellos y los principios o razones que jueguen en sentido contrario».

La ponderación no puede ser cien por ciento racional, buscando una única respuesta al caso concreto, porque a la hora de darle una solución las premisas en choque juegan con unos pesos determinados en un mecanismo procedimental objetivo, que no busca quitarle protagonismo a la discrecionalidad del juez. La ponderación es solo una estructura que está compuesta por 
tres elementos: la ley de la ponderación, la fórmula del peso y las cargas de la argumentación, mediante los cuales se puede fundamentar una relación de precedencia condicionada entre los principios en colisión. Entra así a determinar cuál de los dos principios se debe aplicar al caso concreto, estableciendo de este modo unos pasos para definir el grado de afectación o de satisfacción de uno de dichos principios.

La finalidad de la ponderación como respuesta al conflicto o tensión de derechos en concreto, es la ordenación de los derechos en cuestión, lo cual - siempre de conformidad con las circunstancias de un caso determinadohace posible que el juzgador dé preferencia a cierto derecho sobre otro y, de esta manera, resuelva el conflicto entre ellos. Esta operación de ordenación se plasma en lo que la doctrina denomina «regla de precedencia condicionada» entre los principios en colisión, esto es, la regla que establece las condiciones y requisitos por los cuales un principio debe preceder a otro de conformidad con las circunstancias concretas, vinculando asimismo las consecuencias jurídicas que dicha operación conlleve. Pero dicha regla no puede ser elaborada sin antes constatar ciertos requisitos de procedencia. Estos requisitos son los que encierran el contenido del llamado "test de proporcionalidad» (Baquerizo, 2009: 48 a 50).

La ponderación tiene, por tanto, una dimensión creativa que convierte a este tipo de discurso en un método decisorio en contextos gobernados por principios contrapuestos, pero sometido a límites, y el límite principal es la constitución, dentro de esta los derechos y libertades, y en este orden, la interpretación favorable a los mismos.

En cualquier caso, es preciso subrayar que la ponderación, lejos de representar una novedad aislada en la metodología jurídica del presente, es un ingrediente más dentro de una paleta con la que se está diseñando una nueva forma de aproximarse al derecho, a partir de la constatación de que las constituciones están integradas por un conjunto numeroso y heterogéneo de determinaciones de carácter material que, por una parte, no se relacionan entre sí a partir de órdenes de jerarquía abstracta y, por otra, que generan un efecto irradiación sobre el resto del sistema jurídico.

Ponderar en el derecho constitucional conduce a varios problemas: en primer lugar, el modelo ponderativo quita fuerza normativa a los derechos fundamentales; en segundo lugar, con la teoría de la ponderación el derecho es sacado del ámbito de lo válido y lo inválido, de lo correcto e incorrecto y de lo justificado, y, en último lugar, se trasplanta a uno que sería definido por representaciones ideales como las de una mayor o menor adecuación y conceptos como el de discrecionalidad (Alexy, 2009: 3 a 14). Por ello, hablamos de ponderación en dos sentidos: en sentido amplio es el «modo de argumentación constitucional, por medio del cual el juez resuelve una colisión entre 
valores, objetivos, intereses y/o principios constitucionalmente protegidos. La ponderación se puede llevar a cabo de distintas maneras, es decir, puede consistir en un método más o menos estructurado, con criterios analíticos más o menos precisos para cada paso del método y, por supuesto, con parámetros analíticos que difieren en cuanto a su contenido y su intensidad». En sentido estricto, «es uno de los pasos en la aplicación del principio de proporcionalidad, generalmente el último paso, en el cual el juez lleva a cabo una evaluación del grado en el cual una norma o situación determinada afecta un derecho o principio constitucional, por una parte, y de la importancia de los valores, principios, intereses u objetivos constitucionales invocados para justificar la imposición de dicha carga, por otra».

Respecto a la relación entre la ponderación y la proporcionalidad, como ha indicado Arroyo (2009: 15), una adecuada disección de las relaciones entre ponderación y proporcionalidad exige adoptar como punto de partida la constatación de que estas dos técnicas entran en juego en contextos diferentes. En efecto, ponderación y proporcionalidad no son instituciones homogéneas, y por ello no pueden plantearse como alternativas. Por un lado, la primera es un método decisorio característico de determinados contextos normativos, caracterizados, según se ha señalado, por la preexistencia de un conflicto de normas que no se puede resolver mediante el establecimiento de una relación de preferencia incondicionada. Por otro lado, la segunda es esencialmente un método de control cuya aplicación presupone que la decisión objeto de control ha sido ya adoptada. La propia estructura del principio de proporcionalidad consiste, en efecto, en la aplicación del conocido test tripartito sobre una medida determinada, adoptada de ordinario por un sujeto distinto a aquel que desarrolla el juicio de control ${ }^{11}$.

11 En la segunda mitad de los años noventa se lleva a cabo por parte del TC un deliberado esfuerzo por perfilar las características del principio de proporcionalidad adaptado a las peculiaridades de la litigación constitucional. Las SSTC 66/1995, 55/1996, 207/1996, 161/1997 y 136/19992, procedieron a fijar los elementos del canon de proporcionalidad bajo evidente inspiración alemana. «Para comprobar si la medida impeditiva del ejercicio de un derecho [...] supera el juicio de proporcionalidad exigible, es necesario constatar si cumple los siguientes tres requisitos o condiciones: si tal medida era susceptible de conseguir el objetivo propuesto; si, además, era necesaria en el sentido de que no existía otra medida más moderada para la consecución de tal propósito con igual eficacia, y, finalmente, si la misma era proporcionada, en sentido estricto, es decir, ponderada o equilibrada por derivarse de ella más beneficios o ventajas para el interés general que perjuicios sobre otros bienes o valores en conflicto» (STC 55/1996). 


\section{CRISIS ECONÓMICA Y POLÍTICAS PÚBLICAS COMO NUEVO CANON DE CONSTITUCIONALIDAD}

El canon de constitucionalidad hace referencia a las reglas o criterios que el TC tiene en cuenta a la hora de efectuar el control que constituye su tarea. Esas reglas varían en función del objeto del recurso ante el que nos encontremos (Rodríguez, 2009), pero se reclama un canon o parámetro de control mínimamente operativo que, en el proceso actual de defensa de la constitución, ha reforzado la vigencia del argumento de los principios en el derecho y ha incidido dramáticamente en la configuración de la concepción contemporánea de los derechos fundamentales, con profundas repercusiones en la práctica de su aplicación (Alexy, 2010). Este canon de constitucionalidad o canon de enjuiciamiento, que tiene como fin la defensa de los derechos y, en consecuencia, de la Constitución, no puede ser modificado sin justificación constitucional (Jiménez, 2014: 87 a 113).

En el «voto particular» formulado a la STC8/2015, de 22 de enero ${ }^{12}$, se indica cómo la STC 119/2014, de 16 de julio $^{13}$, ha inaugurado en los razonamientos de la doctrina del TC un novedoso principio interpretativo, y ha decidido elevar a la categoría de canon de constitucionalidad el escenario económico adverso en España. En otras palabras, estas sentencias utilizan la crisis económica como parámetro de valoración constitucional de las medidas limitativas de los derechos constitucionales ubicados en el capítulo II del título I CE — por no hablar de los principios rectores de la política social y económica del capítulo III- acordadas por el legislador. Es, en efecto, el con-

12 Voto particular que formula el magistrado don Fernando Valdés Dal-Ré a la Sentencia dictada en el recurso de inconstitucionalidad núm. 5610-2012, promovido contra a Ley 3/2012, de 6 de julio, de Medidas Urgentes para la Reforma Laboral, al que se adhieren la magistrada doña Adela Asua Batarrita y el magistrado don Luis Ignacio Ortega Álvarez. STC de 22 de enero de 2015.

13 La reforma laboral impuesta en 2012 por el Real Decreto-Ley 3/2012, y posteriormente recogida en la Ley 3/2012, de 6 de julio, de Medidas Urgentes para la Reforma del Mercado Laboral, ha originado la presentación de varios procesos de inconstitucionalidad. Algunos juzgados de lo Social, presentaron cuestiones de inconstitucionalidad contra determinados arts. incluidos en la citada reforma. En total, 16 cuestiones de inconstitucionalidad. Es el caso del Juzgado de lo Social núm. 30 de Madrid, que presentó dos que fueron inadmitidas, o del Juzgado de lo Social núm. 34 también de Madrid, que presentó 14 , también todas inadmitidas. Una de dichas inadmisiones ha sido resuelta por el Auto núm. 043/2014, del 12 de febrero de 2014. Los recursos de inconstitucionalidad, han sido resueltas por STC 119/2014, de 16 de julio, y la Sentencia de 22 de enero de 2015. 
texto de la crisis económica el que justifica restricciones sobre el art. 35.1 CE, o sobre el art. 37.1 CE (FJ 3 b y c de la Sentencia de 22 de enero de 2015, que reenvía a la STC 119/2014, FJ 3 f).Y es esta misma situación la determinante de la desestimación de la vulneración de los arts. 37.1 y 28.1 CE por la nueva regulación del denominado descuelgue salarial (FJ 5.b).

Es este un nuevo canon, de consecuencias impredecibles para la vigencia en nuestro sistema jurídico de las cláusulas sociales. La premisa implícita en este canon es de rápido enunciado: los derechos sociales constitucionales, aunque no se definan como derechos de prestación, están sujetos a un doble juicio de constitucionalidad: uno primero de carácter ordinario, y uno segundo de naturaleza extraordinaria, que se activa en situaciones de crisis económica. Su implantación, en el caso de que constitucionalmente sea admisible, tiene una devastadora potencialidad sobre el desarrollo y consolidación del Estado social, pues pone a disposición del legislador ordinario unas facultades que, no es aventurado entender, podrían terminar hermanándose con las atribuidas al legislador constituyente.

Desde luego, la crisis económica puede validar ciertas limitaciones de los derechos sociales constitucionales, pero tales limitaciones no pueden alterar el contenido esencial de esos derechos ${ }^{14}$. El límite de los límites de los derechos constitucionales debe ser único y uniforme, al margen y con independencia del contexto económico, debiendo mantenerse inalterable a resultas del ciclo económico. El contenido accesorio o no esencial de estos derechos puede acomodarse al entorno económico, pero esa maleabilidad no es predicable de su contenido esencial que, por su propia configuración, ha de estar dotado de una estabilidad al abrigo de los vaivenes de la coyuntura no solo política sino, además, económica.

El test utilizado por la jurisprudencia constitucional para enjuiciar y valorar la conformidad o no de una medida legal que afecte a esos derechos ha venido siendo tradicionalmente el respeto al contenido esencial del mismo. Solo mediante el manejo de este canon, una medida legal podrá ser o no ca-

14 Como ha indicado el Comité Europeo de Derechos Sociales al elaborar las conclusiones sobre las quejas presentadas por nuestras dos organizaciones sindicales más representativas sobre el cumplimiento por la legislación española de la Carta Social Europea (CEDS, conclusions XX-3 (2014), Espagne, janvier 2015): «El Comité considera que las medidas que pretenden consolidar las finanzas públicas, asegurar la viabilidad de los regímenes de pensiones de jubilación o incentivar el empleo podrían estimarse legítimas en tiempos de crisis económica, pero no deben traducirse mediante una reducción de los derechos reconocidos en la Carta», de modo que los gobiernos deben adoptar las medidas necesarias para lograr que «estos derechos sean efectivamente garantizados $[\ldots] »$. 
lificada como lesiva de un derecho fundamental, libertad pública o derecho cívico $^{15}$.

La no utilización del canon del contenido esencial puede implicar la ausencia de dicho contenido cuando, constitucionalmente, todos los derechos tienen un contenido infranqueable por el legislador, y un contenido ilimitable, vedado al legislador, y que es insustituible.

Evidentemente, en su razonamiento el TC recurre a otros cánones de constitucionalidad, como el canon de proporcionalidad, pero el uso del canon de proporcionalidad tiene un carácter complementario, no alternativo, al respeto del contenido esencial, que se constituye en el juicio de constitucionalidad sobre derechos de primer grado. Los derechos pueden ceder ante otros derechos o intereses «constitucionalmente relevantes, siempre que el recorte que aquel haya de experimentar se revele como necesario para lograr el fin legítimo perseguido, proporcionado para alcanzarlo y, en todo caso, sea respetuoso con el contenido esencial del derecho»" ${ }^{16}$.

Como indica el TC en estas resoluciones, es cierto que nos encontramos ante derechos de configuración legal, puesto que no son derechos fundamentales los invocados — al menos directamente- puesto que, de manera indirecta, ciertas regulaciones podrían ser restrictivas de la libertad sindical que proclama el art. $28 \mathrm{CE}$.

No hay que olvidar — afirma el TC—, que el art. 35.2 CE remite a «la ley» la regulación de un estatuto de los trabajadores, por lo que la configuración de los aspectos relativos a las relaciones laborales se defiere al legislador, más concretamente, al legislador estatal ex art. 149.1.7 CE (STC 20/1994, de 27 de enero). Asimismo, también el art. 37.1 CE ordena a «la ley» garantizar el derecho a la negociación colectiva laboral y la fuerza vinculante de los convenios. Es, pues, el legislador el encargado de cumplir un papel activo en la concreción y desarrollo de este derecho, pudiendo establecer limitaciones que «escapan al poder de disposición de las partes negociadoras» (STC 136/1987, de 22 de julio, o STC 208/1993, de 28 de junio). En virtud del art. 53.1 CE es también la «ley» la habilitada para regular el ejercicio de los derechos y libertades reconocidos en el capítulo segundo del título primero de la Constitución, entre los que se encuentran los citados. Por todo ello, a partir de los anteriores presupuestos, resulta constitucionalmente admisible que en la regulación de

15 Entre otras, SSTC: 11/1981, de 8 de abril, FJ 10; 196/1987, de 11 de diciembre, FJ 4; 120/1990, de 27 de junio, FJ 8; 57/1994, de 28 de febrero, FJ 6; 98/2000, de 10 de abril, FJ 5; 70/2002, de 3 de abril, FJ 10.a y 236/2007, de 7 de noviembre, FJ 4.

16 Entre otras, SSTC 143/1994, de 9 de mayo; 98/2000, de 10 de abril; 186/2000, de 10 de julio; 156/2001, de 2 de julio, y 70/2002, de 3 de abril. 
la relación laboral el legislador pueda limitar el alcance de la intervención de la negociación colectiva sobre determinados aspectos o materias.

Sin embargo, entendemos que el TC en su sentencia 8/2015, de 22 de enero contiene una interpretación inadecuada de las potestades del legislador. En su razonamiento, el TC amplía las potestades del legislador, quien, por tratarse de derechos, está limitado en su propia actuación por el contenido esencial de los derechos en juego (art. $53 \mathrm{CE}$ ).

Estando encomendada al legislador la garantía del derecho a la negociación colectiva laboral (art. 37.1 CE), admitiendo que nos encontramos ante «un derecho esencialmente de configuración legal» (STC 85/2001, de 26 de marzo), y siendo la ley la que ha de regular el ejercicio de este derecho por tener reconocidas determinadas potestades en razón de la superior posición que ocupa la ley en la jerarquía normativa, el legislador está limitado para concretar y desarrollar tanto su contenido como los presupuestos para su ejercicio. En «la configuración legal del ejercicio del derecho a negociar», el legislador goza de un cierto margen, pero no, como indica la sentencia, de un amplio margen de libertad para delimitar, como derecho necesario, aspectos de la estructura, contenido, alcance y límites de la negociación colectiva.

El reconocimiento constitucional del derecho a la negociación colectiva no conlleva el desapoderamiento normativo del Estado para regular los aspectos básicos de su ejercicio, y el principio de autonomía colectiva puede presentar excepciones siempre y cuando la limitación que suponga esté justificada (STC 11/1981, de 8 de abril). Por esta razón, la ley «puede desplegar una virtualidad limitadora de la negociación colectiva y puede, igualmente, reservarse para sí determinadas materias que quedan excluidas, por tanto, de la contratación colectiva», pero esta reserva debe ser excepcional (STC 59/1985, de 30 de abril).

La Constitución de 1978 no diseña un modelo cerrado de relaciones laborales, ni más concretamente, de negociación colectiva, correspondiéndole al legislador estatal, en el ejercicio de las funciones que la propia Constitución le confiere, configurar el que considere más idóneo en cada momento (STC 11/1981, de 8 de abril). En esta configuración, puede el legislador elegir entre las distintas alternativas posibles la que estime más adecuada, pero siempre para alcanzar los objetivos que la Constitución le impone, adoptando las medidas precisas que garanticen su realización y para su garantía y defensa, y teniendo en consideración el contenido constitucionalmente declarado.

El constituyente no quiso definir el modelo de relaciones laborales aplicable, ni tampoco restringir la acción del legislador más allá de los límites explícitos que le ha impuesto, dejándole un ámbito de posibilidades para configurar el citado modelo y para articular cada institución que lo integre, pero teniendo en consideración que su actuación constituye un instrumento para 
su desarrollo, y un vehículo a través del cual alcanzar los fines que la Constitución le impone, de acuerdo con su contenido esencial.

La habilitación al legislador estatal para realizar la conceptuación jurídica de los derechos y, en cada momento, entre diferentes alternativas, en atención a las circunstancias económicas subyacentes y a las necesidades sociales a las que se pretenda dar cobertura, como reconoce las sentencias comentadas, no está constitucionalmente justificado, puesto que, además de desconocer el contenido esencial de los derechos, atenta contra el principio de seguridad jurídica.

Las SSTC 119/2014, de 16 de julio, y 8/2015, de 22 de enero, justifican las limitaciones que los preceptos impugnados realizan en los derechos reconocidos en los arts. 35 y 37, en un contexto de crisis económica muy grave, por considerar que son un mecanismo que permite superar la situación que se produce cuando la pretensión de modificar las condiciones de trabajo pactadas en el convenio colectivo para facilitar la adaptación de tales condiciones de trabajo a la productividad y competitividad empresarial, ante la concurrencia de las causas sobrevenidas económicas, técnicas, organizativas o de producción que señala la ley, resulta bloqueada por falta de acuerdo con los representantes de los trabajadores o por el resultado infructuoso de los procedimientos extrajudiciales creados por las representaciones de los trabajadores y de los empresarios para resolver tales desacuerdos, en los términos a los que más adelante se hará referencia. De este modo, entiende el TC, al posibilitar la adaptación de las condiciones laborales a las circunstancias adversas que concurran en una empresa sobrevenidas después de la aprobación del convenio, que el propósito perseguido por el legislador con las medidas cuestionadas ha sido facilitar la viabilidad del proyecto empresarial y evitar el recurso a decisiones extintivas de los contratos de trabajo; esto constituye una finalidad constitucionalmente legítima, atendidos el derecho al trabajo (art. 35.1 CE) y los deberes de los poderes públicos de proteger la defensa de la productividad (art. $38 \mathrm{CE}$ ) y de realizar una política orientada al pleno empleo (art. 40.1 CE) ante la necesidad de afrontar el problema de la grave situación del desempleo en España a la que ya antes se ha hecho alusión (STC 119/2014).

Las sentencias comentadas indican que la medida legislativa cuestionada se dicta en un contexto de grave crisis económica con el objetivo de favorecer la flexibilidad interna de la empresa como alternativa a la destrucción del empleo o al cese de una actividad productiva, atendiendo, de este modo, a un fin constitucionalmente legítimo: tanto el de garantizar el derecho al trabajo de los ciudadanos (art. 35.1 CE) mediante la adopción de una política orientada a la consecución del pleno empleo (art. $40.1 \mathrm{CE}$ ), como la defensa de la productividad de acuerdo con las exigencias de la economía general (art. $38 \mathrm{CE}$ ) (STC 119/ 2014, de 16 de julio) tras llevar a cabo la pertinente ponderación 
de los intereses constitucionales en conflicto y de sus respectivos sacrificios, considerando que los preceptos impugnados contemplan medidas razonables, y que supera las requeridas exigencias de proporcionalidad, en aras de preservar los bienes constitucionales protegidos en los arts. 35.1, 38 y $40.1 \mathrm{CE}$.

\section{UNA LIMITACIÓN EN LOS CRITERIOS INTERPRETATIVOS}

Toda política pública nace de obligaciones objetivas concretas que tienen que obedecer, como finalidad primordial, al resguardo de derechos, tomando como base el respeto a la dignidad de la persona.

En el Estado social y democrático de Derecho, la ratio fundamentalis no puede ser privativa de los denominados derechos de defensa, es decir, de aquellos derechos cuya plena vigencia se encuentra, en principio, garantizada con una conducta estatal abstencionista, sino que es compartida también por los derechos de prestación que reclaman del Estado una intervención concreta, dinámica y eficiente, a efectos de asegurar las condiciones mínimas para una vida acorde con el principio-derecho de dignidad humana.

La garantía del contenido esencial de los derechos constitucionales ofrece, tanto un aspecto negativo de prohibición o limitación al legislador ordinario, cuanto positivo de afirmación.

Si no existe un determinado contenido de un derecho fundamental que vincule y obligue, no sólo como una frontera infranqueable, sino a la vez como directrices de actuación al poder público en general y al legislador en particular (y según las circunstancias, también los particulares), entonces ocurrirá que ese derecho fundamental sólo tendrá, en la realidad, vigencia «formal» pero no material.

La protección que se debe dispensar a los derechos ha de ser efectiva y real y no ilusoria o quimérica, y la interpretación práctica de los derechos fundamentales en la actualidad no puede quedar desligada de la realidad.

En íntima relación con el principio de la protección efectiva y no ilusoria está el de interpretación evolutiva. Este principio constituye un corolario del primero: la protección real y efectiva debe tener en cuenta la mentalidad, los sentimientos y las necesidades sociales del momento, de manera que si estas circunstancias han cambiado, la protección efectiva de los derechos ha de adaptarse a la nueva situación. Y para conseguir esta adecuación, la idea clave es que las constituciones y convenciones constituyen «un instrumento vivo que ha de interpretarse a la luz de las condiciones de hoy» ${ }^{17}$. Por ello, el TEDH entiende que el creciente nivel de exigencia en materia de protección

17 STEDH, caso Marckx c.Bélgica, de 13 de junio de 1979. 
de los derechos humanos y libertades fundamentales implica, de modo paralelo e ineluctable, una mayor firmeza en la apreciación de los atentados a los valores fundamentales de las sociedades democráticas ${ }^{18}$.

Lógicamente, el principio de interpretación evolutiva concede al intérprete un cierto margen de discreción a la hora de apreciar si en el momento de dictar sentencia ha habido algún tipo de cambio de las circunstancias sociales y cuál es exactamente el significado, el peso, la intensidad y la profundidad de ese cambio, y eso refleja una tendencia progresista, pro derechos humanos. Pero importa señalar que la operatividad del principio tiene un límite importante: la constitución ${ }^{19}$.

La interpretación evolutiva puede ser importante, puesto que las normas constitucionales, especialmente en materia de derechos, deben adaptarse a las transformaciones sociales y no pueden quedarse obsoletas (Heller, 1983). La realidad social se puede convertir en punto de partida para situar los postulados constitucionales que deben ser interpretados, pero también es cierto que debe de cuidarse no modificar, con este modelo interpretativo, el propio contenido constitucional y los valores y fines que proclama.

El intérprete, aunque libre en ciertos aspectos en la tarea interpretativa, está sometido a límites, y el límite principal es la propia constitución.

$\mathrm{El}$ intérprete constitucional requiere tener «voluntad de constitución» (Alcalá, 2009: 392 y ss.) para que la carta fundamental adquiera y conserve su realización práctica, incentivando asimismo la formación de sentimiento constitucional (Lucas, 1985), es decir, un vínculo de los ciudadanos con su ordenamiento constitucional, y esta «voluntad de Constitución», se sostiene en tres vertientes: a) la comprensión de la necesidad y del valor del orden normativo constitucional que protege contra la arbitrariedad; b) la comprensión de que el orden constitucional requiere un constante proceso de legitimación, y c) la conciencia de que ese orden constitucional no lograra ser eficaz sin el concurso de las voluntades humanas, adquiriendo y manteniendo su vigencia a través de tales actos de voluntad (Vehweg, 1997: 206).

Un postulado de interpretación constitucional básico, es el de otorgamiento de máxima eficacia o efecto útil a los enunciados normativos constitucionales, lo que exige al intérprete orientarse hacia aquellas alternativas que «optimicen o maximicen la eficacia de las normas constitucionales, sin distorsionar su contenido" (Pérez, 1986: 278), sin dejar de integrar en el análisis todos los componentes del texto constitucional.

18 STEDH, caso Selmouni c. Francia, de 28 de julio de 1999.

19 STEDH, caso Kudla c. Polonia, de 26 de octubre de 2000. 
La «lectura evolutiva o adaptativa de la constitución», no puede dar lugar a que no sea necesaria la rigidez constitucional, que sea superflua la garantía que, al servicio de la rigidez, significa el procedimiento de reforma, e incluso que sobre la distinción entre poder constituyente y poderes constituidos. El TC, entonces, en lugar de ser, como es, un poder constituido, pasaría a ser un poder constituyente permanente ${ }^{20}$.

No podemos olvidar que el operador de la constitución debe interpretar previsoramente teniendo presente las consecuencias de su decisión para el caso concreto, y para el conjunto de la sociedad, lo que, a su vez, otorga razonabilidad al fallo al ponderar los intereses sociales y particulares (Wróblewski' 1985: 114).

El TC más que ningún otro órgano debe extremar la trama argumentativa de sus sentencias: debe basarse en enunciados normativos constitucionales que le otorguen sustento; debe permitir, a través de su línea argumental, que las partes puedan conocer las razones en virtud de las cuales optó en determinada dirección y no en otras (Bielsa, 1998: 976). También debe universalizar los criterios adoptados en la decisión jurisdiccional, y su argumentación debe estar presidida por el recurso a los principios y valores que contempla el orden constitucional y de los postulados específicos de interpretación constitucional

En materia interpretativa, es necesario que los postulados constitucionales sean ajustados a la realidad social, pero no podemos obviar la seguridad jurídica del método formalista y el semántico, aun cuando seamos conscientes de sus limitaciones en los casos difíciles y problemas constitucionales. El enfoque material y teleológico debe ser considerado por el énfasis dado a los valores y fines que deben tomarse en cuenta al aplicarse la constitución, siempre y cuando no vaya en desmedro de la legalidad constitucional. Tampoco podemos obviar el valor de la coherencia impuesto por la interpretación sistemática, lo cual es comprensible, considerando que la constitución está a la cabeza del orden constitucional de cualquier país.

La interpretación evolutiva y el enfoque realista son importantes en la tarea de ajustar la constitución a las necesidades sociales actuales y considerar el contexto y la realidad social existente, a fin de darle vigencia plena y dura-

20 Voto particular que presenta el magistrado Aragón Reyes a la STC 198/2012, de 6 de noviembre, en la que, además, indica: «Como esto no puede ser así, por razones obvias, pues, el Tribunal Constitucional es el supremo intérprete de la Constitución, pero no su supremo dueño, y es difícil aceptar que así lo quisieran los demás magistrados de la mayoría, no hay más remedio que entender que ha sido, más que un error, fruto de la inadvertencia, realizar estas afirmaciones sin modularlas, limitarlas, precisarlas con los necesarios matices y cautelas para que no surtan los efectos perniciosos que, dichas en términos tan generales como se dicen, podrían provocar». 
dera a la constitución, siempre y cuando esta interpretación no vaya en contra de valores y principios expresamente establecidos en el texto constitucional, cuestión para la cual será exigible una reforma constitucional.

La interpretación constitucional debe alejarse de los deseos del que la interpreta en cada momento.

Como señala Gadamer (1984: 382), «la interpretación no es un acto complementario a la comprensión, sino que comprender es siempre interpretar y, en consecuencia, la interpretación es la forma explícita de la comprensión».

La interpretación por sí misma no puede cambiar la constitución. La interpretación jurídica, en cualquiera de sus formas, es un modo de comprensión, que es una modalidad de conocimiento. Comprender es conocer algo en su ser cuando este ser es un ser sentido, e interpretar y comprender el objeto cultural ya creado. La interpretación busca conocer el objeto de conocimiento tal como se presenta, sin modificarlo.

La interpretación de la constitución hay que realizarla conforme a la propia constitución, con las distintas reglas de interpretación que permitan su validez y su vigencia, pero con parámetros constitucionales, puesto que no podemos dejar la constitución a merced de un órgano constituido creado por el poder constituyente. Si se suprime el poder constituyente se destruye la constitución, no se construye, ni se muta, ni se reforma, y se supera la idea, central en el constitucionalismo democrático, de que la reforma es una técnica específica de limitación del poder con intención de garantía (Mora-Donatto, 2002).

El juez no puede ser un aplicador frío de la letra de la ley, pues bajo el impacto de circunstancias no previstas por el legislador hay que ver en la ley no una letra muerta, sino un tejido vivo, capaz de reacciones nuevas ante nuevas situaciones; pero el poder de reforma, un poder constituido, representa el imperio del derecho en una sociedad que ha llegado a unos acuerdos mínimos y ha decidido transitar en paz al amparo del poder institucionalizado, por lo que no podemos pretender que el poder reformador asuma la actividad del poder constituyente o imite sus funciones, lo cual es tanto como pretender que la normalidad del derecho siga la incertidumbre de los hechos (Rodríguez, 2006: 109).

El respeto de la constitución exige que no podamos asumir su mutación por situaciones de facto, o por el puro avance social. Ante el desarrollo de la sociedad, los problemas jurídicos planteados exigen su reforma, como mecanismo jurídico que produce seguridad entre la sociedad y respeto constitucional.

La labor del TC al interpretar derechos tiene que partir del contenido esencial constitucionalmente declarado, y debe aplicar el test de proporciona- 
lidad, que se compone de los subprincipios de adecuación, necesidad y proporcionalidad en sentido estricto; todos estos subprincipios expresan la idea de optimización. Los derechos fundamentales son mandatos de optimización, y como tales son normas de principio que ordenan la realización de algo en la más alta medida, relativamente a las posibilidades materiales y jurídicas (González, 2003).

Debe, además, ponderar, pero tomando la idea de que la ponderación se realiza respecto a normas, principios o reglas que se sitúan en planos similares. En las sentencias en comentario, la labor de ponderación se realiza no solo entre los derechos constitucionales reconocidos en la sección segunda del capítulo II del título I —en este caso los derechos reconocidos en los arts. 35 y 37 - sino también con relación a derechos fundamentales, la libertad sindical reconocida en el art. $28 \mathrm{CE}$, y también con relación al principio rector del pleno empleo, art. 40 CE (Carrasco, 1984: 39 y ss.).

La ponderación es una parte de lo que exige un principio más amplio; este principio comprehensivo es el de proporcionalidad, que permite identificar una serie de requisitos que resultan, todos ellos y en conjunto, aplicables a toda intervención en la libertad de las personas por parte del poder público, sea del legislador, del poder ejecutivo o del poder judicial y de los intérpretes constitucionales (Barnés, 1988): debe perseguir una finalidad legítima; debe ser adecuada o idónea para la promoción (no necesariamente la realización) de dicho objetivo legítimo (adecuación); debe ser necesaria, y entre varias alternativas de intervención debe preferirse la que afecte menos a los derechos involucrados (mínimo de intervención), y debe ser proporcional en sentido estricto, es decir, la gravedad de la intervención ha de ser la adecuada al objetivo de la intervención. Por tanto, los instrumentos y los medios aplicados deben justificarse en su grado de gravedad: la gravedad de las intervenciones debe ser proporcionada a la urgencia o necesidad de los objetivos. Si estos no son urgentes o no son muy necesarios, los instrumentos utilizados deben ser de menor intensidad (relación). Este último requisito parece ser el más importante para la protección de la libertad. Conlleva una ponderación entre el interés del individuo, manifestado en su derecho fundamental, y el interés público. Esta ponderación debe tener en cuenta la situación particular del individuo y, desde luego, no puede suponer la anulación o negación del derecho.

Una decisión del TC como la adoptada en las sentencias objeto de comentario, en las que adecúa la ley al momento presente, con un modelo laboral inserto en un momento de crisis, obviando el contenido esencial del derecho, implica recurrir solo a uno, siendo magnánimos en su admisión, de los criterios de proporcionalidad — la posible adecuación — olvidando el resto de aquellos criterios que le otorgan su plena validez. Con ello, difícilmente se consigue una proporcionalidad adecuada y justa entre las medidas adoptadas 
y el respeto a los derechos, con lo cual se limita más allá de donde se puede limitar.

El principio de proporcionalidad, también conocido como "proporcionalidad de injerencia» o "prohibición de exceso», es un principio de naturaleza constitucional que permite medir, controlar y determinar que las injerencias directas o indirectas de los poderes públicos sobre el ámbito o esfera de los derechos de la persona respondan a criterios de adecuación, coherencia, necesidad, equilibrio y beneficio entre el fin lícitamente perseguido y los bienes jurídicos potencialmente afectados o intervenidos, de modo que sean compatibles con las normas constitucionales. Se trata, por tanto, de una herramienta hermenéutica que permite determinar la constitucionalidad de la intervención o restricción como de la no intervención de los poderes públicos sobre los derechos fundamentales.

Como ha indicado la STC 85/1982, de 28 de junio, la relevancia del criterio de proporcionalidad como principio inherente del Estado de derecho en su condición de canon de constitucionalidad, tiene especial aplicación cuando se trata de proteger derechos frente a las limitaciones o constricciones, procedan estas de normas o resoluciones singulares. La regla de proporcionalidad de los sacrificios es de observancia obligada al proceder a la limitación de un derecho (STC 37/1989), lo que nos conduce a negar legitimidad constitucional a las limitaciones o sanciones que incidan en el ejercicio de los derechos de forma poco comprensible, de acuerdo con una ponderación razonada y proporcionada, y a exigir que toda actuación deslegitimadora del ejercicio de un derecho en beneficio de otro, o de un fin o una regla, sea equilibradora de ambos y proporcionada con el contenido y finalidad de cada uno de ellos (Perelló, 1997: 69 y ss. y 2003: 75 y ss.).

En cualquier juicio de constitucionalidad que se realice, es necesario utilizar el juico de proporcionalidad porque está orientado a resolver conflictos entre derechos, intereses o valores en concurrencia. En las sentencias que estudiamos, el juicio de proporcionalidad se debe realizar en relación con la colisión de los derechos en conflicto: el derecho del trabajo y la libertad de empresa y, tras la configuración del contenido esencial de ambos derechos, se debe ponderar cuál es el conflicto entre los derechos en juego sin que la situación de crisis económica sea un nuevo criterio limitativo de derechos, puesto que en situaciones de crisis económicas de extraordinaria gravedad o para hacer frente a la lucha contra la inflación, lograr el equilibrio de la balanza de pagos, etc., los gobiernos han recurrido a políticas económicas agresivas contra los derechos de los trabajadores, sin que ello sea justificable, ni favorablemente interpretable sin la aplicación del consiguiente canon de constitucionalidad. Aceptar estas resoluciones no adecuadamente razonadas ni ponderadas, supone legitimar las decisiones políticas gubernamentales que puedan afectar a 
derechos y libertades constitucionales (Mercader, 2008: 127 a 146). El intérprete constitucional no puede colocarse en la posición del Ejecutivo, pues no esa su tarea, sino, precisamente, ejercer el control constitucional en la labor gubernamental.

El principio de proporcionalidad tiene su fundamento valorativo en el orden constitucional, en tanto se convierte en el criterio de equilibrio o modulación entre las acciones que el Estado realiza en el cumplimiento de sus fines y el respeto de los derechos. Ello significa que el principio de proporcionalidad adquiere plena justificación en el ámbito de la actuación de los poderes públicos, en tanto se explicita como filtro de armonía que impide que la actividad del Estado sobrepase los límites exigibles para la consecución de los intereses colectivos cuando los derechos son limitados sin fundamento. El principio de proporcionalidad se constituye en un mecanismo jurídico de trascendental importancia en el Estado constitucional y como tal tiene por función controlar todo acto de los poderes públicos en los que puedan verse lesionados los derechos fundamentales, entre otros bienes constitucionales (Fernández 2009).

Hoy en día, tanto la doctrina como la jurisprudencia constitucional han admitido que no existen derechos ilimitados, sino que todo derecho tiene sus límites (STC 11/1981, de ocho de abril). Se ha defendido la existencia de límites internos de los derechos y libertades, aquellos que derivan del propio concepto del derecho y de las facultades que de él se derivan, y límites externos, derivados no del propio concepto del derecho o libertad, pero necesarios para proteger este propio concepto o bienes protegidos constitucionalmente (Martín Retortillo y De Otto, 1988).

En cualquier caso, se trata de límites que sólo pueden tener cobertura constitucional. Solamente se puede imponer límites a los derechos que estén reconocidos en sede constitucional. La determinación del contenido de los derechos ha de inferirse de la propia constitución en el marco de una interpretación constitucional que también tenga en cuenta aquellos criterios axiológicos y teleológicos a los que responde la propia norma suprema. Evidentemente, el propio contenido interno del derecho, o la propia constitución expresamente, parece imponer límites que, en muchos casos, no constituyen límites en sentido estricto, sino que forman parte de la delimitación conceptual del propio derecho. En definitiva, se trata de «limitaciones» que pueden no entenderse como tales, sino que pueden ser consideradas como parte del propio contenido de un derecho o de una libertad, y que, en cualquier caso, derivan de la propia constitución.

Y lo mismo puede predicarse respecto de los límites externos que podemos encontrar en las declaraciones de derechos y otros acuerdos internacio- 
nales $^{21}$. Se trata de límites emanados de normas que, por derivación del art. 10.2, sirven de criterio interpretativo para las normas que regulen derechos y libertades que la Constitución reconoce y que, por formar parte del ordenamiento jurídico español (art. $96 \mathrm{CE}$ ), tienen cobertura constitucional. El TC tiene que considerar que en el juicio de constitucionalidad que le corresponde realizar, se encuentran condicionamientos internacionales y comunitarios: "Compromisos internacionales a los que se encuentra vinculado el legislador, cuando las normas comunitarias o los tratados internacionales, pactos, protocolos, etc., pasan a formar parte de nuestro derecho interno».

En lo que a la justificación se refiere, y partiendo de que los únicos límites admitidos tienen que estar previstos o tener cobertura constitucional, la limitación de derechos o libertades sólo puede justificarse «por la necesidad de proteger o preservar [...] otros derechos constitucionales [...] u otros bienes constitucionalmente protegidos» (STC 2/1982, de 29 de enero), y además debe tratarse de bienes que no pueden ser identificados de forma general con cualquier fin, bien o interés, sino que deben de derivar de valores constitucionales, puesto que si así no fuera, como ha afirmado el TC (STC 22/1984, de 17 de febrero), ello «sería inconciliable con los valores superiores del ordenamiento jurídico que nuestra Constitución proclama. [...] ha de tratarse de fines sociales que constituyan en sí mismos valores constitucionalmente reconocidos y la prioridad ha de resultar de la propia Constitución». Ante esta afirmación, una situación de crisis económica no justifica cualquier decisión política del Gobierno como medida limitativa de derechos y libertades.

21 «En el ejercicio de sus derechos y en el disfrute de sus libertades, toda persona estará solamente sujeta a las limitaciones establecidas por la ley con el único fin de asegurar el reconocimiento y el respeto de los derechos y libertades de los demás, y de satisfacer las justas exigencias de la moral, del orden público y del bienestar general en una sociedad democrática (art. 29.2 Declaración Universal de Derechos Humanos)».

«El ejercicio de estas libertades, que entrañan deberes y responsabilidades, podrá ser sometido a ciertas formalidades, condiciones, restricciones o sanciones, previstas por la ley, que constituyan medidas necesarias, en una sociedad democrática, para la seguridad nacional, la integridad territorial o la seguridad pública, la defensa del orden y la prevención del delito, la protección de la salud o de la moral, la protección de la reputación o de los derechos ajenos, para impedir la divulgación de informaciones confidenciales o para garantizar la autoridad y la imparcialidad del poder judicial (art. 10.2. del Convenio Europeo de Derechos Humanos)».

«La libertad [...] estará sujeta, únicamente, a las limitaciones prescritas en la ley que sean necesarias para proteger la seguridad, el orden, la salud o la moral públicos o los derechos y libertades fundamentales de los demás» (art. 18.3 del Pacto Internacional de Derechos Civiles y Políticos). 
Evidentemente, el legislador puede optar al regular derechos y libertades por una de las posibles opciones puesto que, aunque constitucionalmente está obligado a respetar el contenido esencial de los derechos, forma parte del ejercicio del poder político. Pero el TC, en cuanto garante último de los derechos y libertades y como intérprete supremo, cuando resuelve las dudas de inconstitucionalidad que le son planteadas, debe utilizar las reglas adecuadas al respeto al contenido esencial de los derechos, que debe ser examinado en cualquier resolución de esta naturaleza para, de manera razonada y razonable, reconocer límites proporcionales y proporcionados y la situación política, económica o social que puede ser tomada en consideración, y que exige una actividad especialmente respetuosa con la aceptación de límites, puesto que puede determinar cambios en el modelo de derechos que conlleven mutaciones constitucionales, para lo que no está legitimado el intérprete constitucional.

La ponderación no permite al juez constitucional elegir libremente cómo se ha de dar prioridad a un derecho frente a otro. Este ha de tener en cuenta, en primer lugar, que debe dar la máxima amplitud a todos los principios que entran en conflicto y tiene que procurar que estos tengan la mayor eficacia en la colisión planteada. Los principios se conforman como mandatos de optimización que deben ser aplicados en la medida en que sea posible jurídica y fácticamente, por lo que el intérprete debe otorgar la máxima eficacia a todos los derechos que entran en conflicto.

Solo donde la constitución pone límites, puede poner límites el legislador, y éstos siempre tienen que tener, como base constitucional, bien los derechos y libertades de otras personas, bien los valores superiores proclamados constitucionalmente y respecto de los cuales, los derechos y libertades son su concreción práctica. Esta base constitucional del respeto a los valores constitucionales y del respeto de los derechos y libertades ajenos permite que la propia constitución pueda establecer excepciones al ejercicio de derechos y libertades.

El respeto al contenido esencial y el principio de proporcionalidad, gozan de un relevante cariz constitucional de primer orden y constituyen canon de constitucionalidad de los poderes públicos, que deberán acomodar a ellos su actuación, procediendo en la resolución de todo conflicto a una cuidadosa ponderación de las circunstancias de todo orden que concurran en cada caso concreto, absteniéndose de cualquier posible exceso susceptible de traducirse en un sacrificio innecesario e injustificado de un derecho.

Toda actuación de los poderes públicos, en especial de los intérpretes de la constitución, debe ajustarse a un canon de racionalidad que, a través del canon de proporcionalidad, respete los valores y principios constitucionales y el propio texto constitucional, como elementos principales de la defensa constitucional (Ruggieri, 2005). 
La interpretación de la constitución no es una actividad que quede libre de límites, que serían una especie de garantías últimas frente a interpretaciones irregulares. En tanto se trata de una tarea que realizan los poderes constituidos, la interpretación que por ellos se lleve a cabo no puede contradecir la labor realizada por el poder constitucional, que se encuentra en la propia constitución (Atienza, 2005). Desde esta perspectiva, cuando una constitución señala el proceso especial a través del cual es posible su reforma, está excluyendo la posibilidad de que se genere un derecho constitucional consuetudinario mediante la jurisprudencia constitucional, así como la modificación de la constitución mediante una interpretación del TC.

La interpretación constitucional es de suma importancia, en primer lugar porque la constitución constituye el cimiento del Estado de derecho, además de por el carácter abierto y amplio de las normas constitucionales y su naturaleza eminentemente política en su origen, contenido y función. Las decisiones interpretativas del juez constitucional están sujetas a ciertos límites, que estarían constituidos por los límites de validez y los límites de corrección (Prieto, 1987: 123 y ss.), pues la ausencia de límites a las decisiones interpretativas, llevado a sus últimas consecuencias, deja sin sentido la propia existencia del texto constitucional. Así, si el intérprete puede atribuir cualquier significado al texto o enunciado normativo, la preexistencia de este ya no es necesaria (De Asís, 2004: 298 y 299). Toda actividad constitucional debe ser razonable. Los principios, valores, derechos y garantías constitucionales no pueden ser alterados por procesos interpretativos, puesto que se incurriría en arbitrariedad (Díaz, 1997).

Existen criterios racionales que nos permiten identificar una interpretación irregular del marco de sentidos posibles de la constitución, en especial del tratamiento que esta otorga a los derechos y libertades, y dichos criterios son el respeto al contenido esencial y el juicio de proporcionalidad y los criterios de ponderación.

La concepción de la existencia de límites a la justicia constitucional parte de la premisa de que la interpretación constitucional debe ser una tarea sujeta a restricciones. Los derechos constituyen una herramienta interpretativa sui géneris por su especial calidad constitucional. La actividad limitadora de los derechos fundamentales solo puede provenir de la propia constitución y, en la medida en que la constitución lo prevea, del legislador, siendo incompatibles con el ordenamiento constitucional otras fuentes de limitación por su calidad de disposiciones subordinadas. Los principios de interpretación constitucional —unidad de la constitución, concordancia práctica, corrección funcional, función integradora y primacía normativa de la constitución, además del respeto al contenido esencial de los derechos, de la ponderación y el principio de proporcionalidad - se constituyen en las únicas herramientas interpretativas válidas. 


\section{BIBLIOGRAFÍA}

Alcalá Nogueira, N. (2009). Las mutaciones de la Constitución producidas por la interpretación del Tribunal Constitucional. ¿¿El TC, poder constituido o poder constituyente en poder permanente? Estudios Constitucionales, (2), 127-149.

Alexy, R. (2007). Teoría de los derechos fundamentales. Trad.n y estudio introductorio de Carlos Bernal Pulido, 2a ed. Madrid: CEPC.

- (2009) Derechos fundamentales, ponderación y racionalidad, Trad. de Rubén Sánchez Gil. Revista Iberoamericana de Derecho Procesal Constitucional, (11), 3-14.

- (2010). Derechos fundamentales, ponderación y racionalidad. En L. García Jaramillo, L. y M. Carbonell, (eds.). El canon neoconstitucional. Bogotá: Universidad Externado de Colombia.

Alfonso da Silva, V. (2005). La Interpretación conforme a la Constitución. Entre la Trivialidad y la Centralización Judicial. Cuestiones Constitucionales, (12), 3-28.

Alzaga Villamil, O. et al. (2013). Derecho Politico Español. Tomo I. Madrid: CERA.

Aragón Reyes, M. (1986). La interpretación de la Constitución y el carácter objetivado del control jurisdiccional. Revista Española de Derecho Constitucional, (17), 85-36.

Arroyo Jiménez, L. (2009). Ponderación, proporcionalidad y Derecho Administrativo. InDret, (2): 1-32.

Asís Roig, R. (2004). La interpretación de la Constitución: sobre cómo interpretar y sobre quién debe ser su intérprete. En G. Peces-Barba Martínez y M. A. Ramiro Avilés (coords.). La Constitución a examen: un estudio académico 25 años después. Madrid: Instituto de Derechos Humanos Bartolomé de las Casas, Marcial Pons.

Atienza, M. (2005). Los limites de la interpretación constitucional. De nuevo sobre los casos trágicos. Alicante: Biblioteca Virtual Miguel de Cervantes.

Balaguer Callejón, M. L. (1997). Interpretación de la Constitución y Ordenamiento Jurídico. Madrid: Tecnos.

Baquerizo Minuche, J. (2009). Colisión de derechos fundamentales y juicio de ponderación. Revista de Derecho Público, (1), 19-52.

Barnés, J (coord). (1998). El principio de proporcionalidad (número monográfico). Cuadernos de Derecho Público, (5).

Baura, E. (1987). El contenido esencial del derecho constitucional al matrimonio. IUS CANONICUM, 27 (54), 697-739.

Betti, E. (1975). Interpretación de la Ley y de los Actos Jurídicos. Madrid: Editorial Revista de Derecho Privado.

Bernal Pulido, C. (2005). El principio de proporcionalidad y los derechos fundamentales, 2a ed. Madrid: CEPC.

Bielsa, M. (1998). Tratado de Interpretación Constitucional. Buenos Aires: Abeledo.

Canosa Usera, R. (1988). Interpretación constitucional y fórmula politica. Madrid: Centro de Estudios Constitucionales.

Capitánt, H. (1930). Vocabulario Jurídico. Buenos Aires: Ediciones Depalma.

Carbonell, M. (ed.). (2008). El principio de proporcionalidad y la interpretación constitucional. Quito: Ministerio de Justicia y Derechos Humanos. 
Carpio Marcos, E. (2004). La Interpretación de los Derechos Fundamentales. Lima: Palestra editores.

Carpizo, J. (2009). El Tribunal Constitucional y sus limites. Lima: Grijley.

Carrasco Perera, A. (1984). El 'juicio de razonabilidad' en la Justicia Constitucional. Revista Española de Derecho Constitucional, (11), 39-106.

De Otto y Pardo, I. (1988). La regulación del ejercicio de los derechos y libertades. La garantía de su contenido esencial en el artículo 53.1 de la Constitución. En L. Martín-Retortillo y I. de Otto y Pardo. Derechos fundamentales y Constitución. Madrid: Cuadernos Cívitas Derecho Constitucional.

Díaz Revorio, F.J. (1997). Valores superiores e interpretación constitucional, Madrid: Centro de Estudios Constitucionales.

Dworkin, R. (1999). Los derechos en serio. Barcelona: Editorial Ariel.

Fernández Nieto, J. (2009). El principio de proporcionalidad y derechos fundamentales: una visión desde el sistema europeo. Madrid: Dykinson.

Fernández Segado, F. (1995). La dignidad de la persona humana en el ordenamiento constitucional español. Revista Vasca de Administración Pública, (43), 49-79.

Gadamer, H.G. (1984). Verdad y método. Salamanca: Sígueme.

Galán Suárez, M. (2006). La interpretación de los derechos fundamentales por parte del Tribunal Constitucional. Una argumentación en términos de razonabilidad. Isegoría: Revista de Filosofía Moral y Política, (35): 33-55.

García Herrera, M. A. (1979). Principios generales de la tutela de los derechos y libertades en la Constitución española. Revista de la Facultad de Derecho de la Universidad Complutense, núm. Monográfico, 95-122.

Gavara de Cara, J. C. (1994). Derechos fundamentales y desarrollo legislativo. La garantía del contenido esencial de los derechos fundamentales en la Ley Fundamental de Bonn. Madrid: Centro de Estudios Constitucionales.

González Beilfuss, M. (2003). El Principio de Proporcionalidad en la Jurisprudencia del Tribunal Constitucional,. Cizur Menor: Thomson-Aranzadi.

Häberle, P. (1990). El legislador de los derechos fundamentales. En A. López Pina (ed.). La garantía constitucional de los derechos fundamentales: Alemania, España, Francia e Italia, Madrid: Cívitas, Universidad Complutense.

Häberle, P. (1997). La libertad fundamental en el Estado Constitucional. Lima: Fondo Editorial de la PUCP.

Haro, R. (2001). La razonabilidad y las funciones de control. Ius et Praxis, 2 (7), 179-186. Disponible en: $h t t p: / / d x$.doi.org/10.4067/s0718-00122001000200008.

Héller, H. (1983). Teoría del Estado. México: Fondo de Cultura Económica.

Jiménez Compaired, I. (2014). La modificación del canon de constitucionalidad en los procedimientos de declaración de inconstitucionalidad de normas financieras y tributarias. Crónica Tributaria, (151), 89-113.

Linares Quintana, S. (1998). Tratado de interpretación constitucional. Buenos Aires: Abeledo Perot.

Lorenzo Rodriguez-Armas, M. (1996). El problema del contenido esencial de los derechos fundamentales en la doctrina española y su tratamiento en la jurisprudencia constitucional. Anales de la Facultad de Derecho, (13), 41-76. 
Lothar M. (2009). ¿El contenido esencial como común denominador de los derechos fundamentales en Europa? Revista de Derecho Constitucional Europeo, (11). Disponible en: http://www.ugr.es/ redce/REDCE11/ReDCEsumario11.htm.

Lucas Verdú, P. (1985). El sentimiento constitucional (Aproximación al estudio del sentir constitucional como modo de integración política). Madrid: Reus.

Maldonado Muñoz, M. (2012/2013). El principio de razonabilidad y su aplicación al estudio de validez de las normas jurídicas. Ius Humani. Revista de Derecho, (3), 139-174.

Martínez-Pujalte. A.L. (1997). La garantía del contenido esencial de los derechos fundamentales. Madrid: Centro de Estudios Constitucionales.

Martínez, J. I. y Zúñiga Urbina, F. (2011). El principio de razonabilidad en la jurisprudencia del Tribunal Constitucional. Estudios Constitucionales, 9 (1), 199-226. Disponible en: http://dx.doi.org/10.4067/S0718-52002011000100007.

Martín-Retortillo, L y De Otto y Pardo, I. (1988). Derechos fundamentales y Constitución. Madrid: Cuadernos Cívitas.

Medina Guerrero, M. (1996). La vinculación negativa del legislador a los derechos fundamentales. Madrid: McGraw-Hill.

Medina Guerrero, M. (1998). El principio de proporcionalidad y el legislador de los derechos fundamentales. Cuadernos de Derecho Público, 5, 119-142.

Mercader Uguina, J. R. (2008). Tutela judicial efectiva, control de razonabilidad de las decisiones judiciales y 'canon reforzado' de motivación en la doctrina del Tribunal Constitucional. Revista del Ministerio de Trabajo y Asuntos Sociales, 73, 127-146.

Mora-Donatto, C. (2002). El valor de la Constitución normativa. México: UNAM.

Nogueira Alcalá, H. (2008). Derechos fundamentales y garantías constitucionales. Dogmática de los derechos fundamentales, interpretación de derechos y derechos de la personalidad, t. I. Santiago: Librotecnia.

Ollero Tassara, A. (1996). ¿Tiene razón el Derecho? Madrid: Congreso de los Diputados.

Parejo Alfonso, L. (1981). El contenido esencial de los Derechos Fundamentales en la Jurisprudencia Constitucional; a propósito de la Sentencia del Tribunal Constitucional de 8 de abril de 1981. Revista Española de Derecho Constitucional 3, 169190.

Perelló Domenech, I. (1997). El principio de proporcionalidad y la jurisprudencia constitucional. Jueces para la Democracia, 28, 69-95.

- (2003). Notas sobre el concepto de razonabilidad y su uso en la jurisprudencia constitucional. Jueces para la Democracia, 46, 75-82.

Pereira Menaut, A. C. (2006). Teoría Constitucional, 2a ed. Santiago: Lexis Nexis.

Pérez Luño, A. (1986). Derechos Humanos, Estado de Derecho y Constitución. Madrid: Tecnos.

Pérez Royo, J. (1997). Curso de Derecho Constitucional. Madrid: Marcial Pons.

Prieto Sanchís, L. (1984). Artículo 53. Protección de los Derechos Fundamentales. En O. Alzaga Villaamil (dir.). Comentarios a las Leyes Políticas, t. IV. Madrid: Editorial Revista de Derecho Privado.

Prieto Sanchís, L. (1987). Ideología e interpretación jurídica. Madrid: Tecnos.

- (2003). Justicia Constitucional y Derechos Fundamentales. Madrid: Trotta. 
Rodríguez Carbajo, J. R. (2009). El canon de constitucionalidad de las decisiones judiciales que inadmitan recursos de casación. Actualidad Administrativa, 19, 18-20.

Rodríguez Gaona, R. (2006). El control constitucional a la reforma de la Constitución. Madrid: Dikynson.

Ruiz-Giménez Cortés, J. (1997). Artículo 10. Derechos Fundamentales de la persona. En O. Alzaga VIllaamil (dir.). Comentarios a la Constitución española de 1978, t. II. Madrid: Cortes Generales, Edersa.

Ruggieri, A. (2005). Reforma de la Constitución y control de constitucionalidad. Bogotá: Pontificia Universidad Javeriana.

Sánchez Gil, R. (coord.) (2007). El principio de proporcionalidad. México: UNAM.

- (2009). Recepción jurisprudencial del principio de proporcionalidad en México. Cuestiones Constitucionales, 21, 471-489.

Sapag, M.A. (2008). El principio de proporcionalidad y de razonabilidad como límite constitucional al poder del Estado: un estudio comparado. Dikaion, 17, 157-198.

Vehweg, T. (1997). Tópica y Filosofa del Derecho. Barcelona, Gedisa.

Wróblewski, J. (1985). Constitución y Teoría General de la Interpretación Jurídica. Madrid: Civitas. 